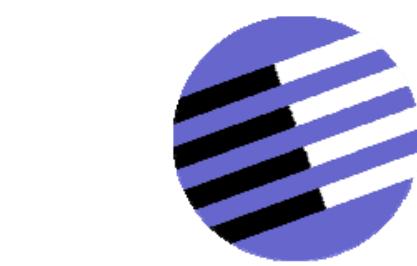

GOVERNANCE AND THE EFFICIENCY

OF ECONOMIC SYSTEMS

GESY

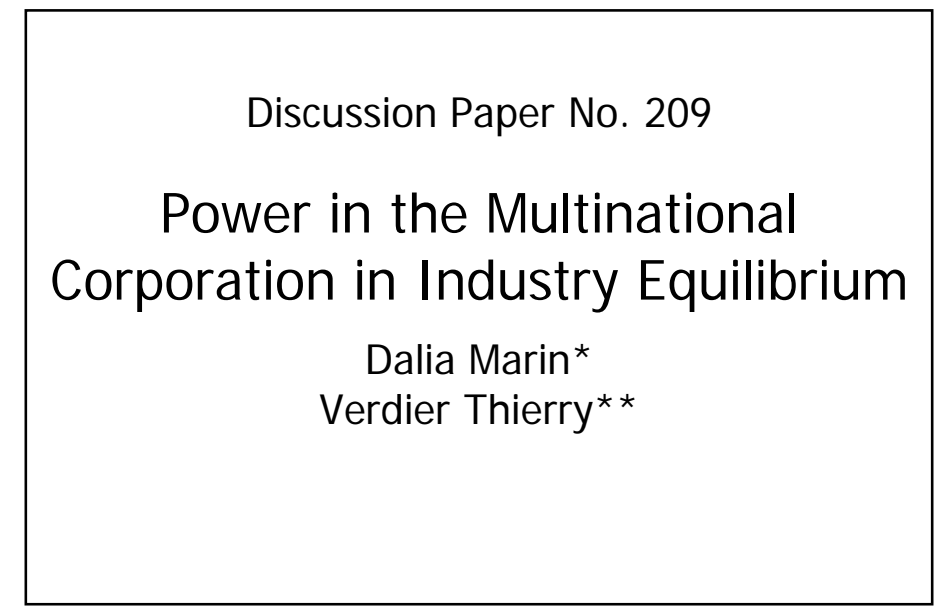

May 2007

*Dalia Marin, University of Munich, Department of Economics, Ludwigstr. 28, 80539 Munich, Germany +49-89-2180-2446, dalia.marin@Irz.uni-muenchen.de **Verdier Thierry, Paris School of Economics, 48 Boulevard J ourdan, 75014 Paris, France, +331-43-13-63-08, verdier@pse.ens.fr

Financial support from the Deutsche Forschungsgemeinschaft through SFB/TR 15 is gratefully acknowledged. 


\title{
Power in the Multinational Corporation in Industry Equilibrium*
}

\author{
Dalia Marin, University of Munich \\ Thierry Verdier, Paris School of Economics
}

May 2007

\begin{abstract}
Recent theories of the multinational corporation introduce the property rights model of the firm and examine whether to integrate our outsource firm activities locally or to a foreign country. This paper focus instead on the internal organization of the multinational corporation by examining the power allocation between headquarters and subsidiaries. We provide a framework to analyse the interaction between the decision to serve the local market by exporting or FDI, market acces and the optimal mode of organization of the multinational corporation. We find that subsidiary managers are given most autonomy in their decision how to run the firm at intermediate levels of local competition. We then provide comparative statics for changes in fixed FDI entry costs and trade costs, information technology, the number of local competitors, and in the size of the local market.
\end{abstract}

JEL classification: D23; F1; F2

Keywords: foreign direct investment, power allocation in the firm, international trade and the organization of production

*Acknowledgement: Financial support from the Deutsche Forschungsgemeinschaft through SFB/TR 15 and DFG-Ma 1823/3-1 is gratefully acknowledged. 


\section{Introduction}

Recent theories of the multinational corporation open up the black box of the firm by incorporating theories of the firm in models of the multinational corporation. Antras (2003) and Antras and Helpman (2004) introduce the property rights model of the firm (Grossman and Hart (1986), Hart and Moore (1990)) into a model of the multinational corporation. They examine questions of the boundaries of the multinational firm by analysing the decision whether to integrate or outsource firm activities locally or to a foreign country. This paper focus instead on the internal organization of the multinational corporation. We introduce a variant of the Aghion and Tirole (AT) (1997) model of the firm into a monopolistic competition model of the multinational corporation. We provide a framework to analyse the interaction between delegating power to the manager in the foreign subsidiary, market access, and the decision whether to enter a foreign market via exporting or foreign direct investment $(\mathrm{FDI}){ }^{1}$

In previous papers we model how international trade is affecting the internal organization of national firms. In Marin and Verdier (2007a, 2006) we introduce a variant of the Aghion and Tirole model into a Krugman (1980) cum Melitz and Ottaviano (2006) model of international trade to examine how international trade is affecting internal hierarchies of firms in similar countries (North-Nort trade). In Marin and Verdier (2003) we incorporate AT in a Helpman and Krugman (1985) model of trade to analyse how international trade between countries which differ in factor endownments (North-South trade) is affecting the allocation of power inside firms. In Marin and Verdier (2007b) we are reversing the question and we are asking how corporate organization is affecting firm performance and the nature of competition in international markets.

The paper is organised in the following sections. In section 2 we consider the allocation of decision power inside a multinational firm between its headquarter and the local management of its subsidiary. We determine the multinational firm's

\footnotetext{
${ }^{1}$ McLaren (2000) is a first attempt to analyse the question of integration and outsourcing in an international trade framework. Antras, Garicano, Rossi-Hansberg (2006) and Grossman and Rossi-Hansberg (2006) focus also on the internal organization of the multinational corporation by examining the formation of international teams. Puga and Trefler (2005) use also the Aghion and Tirole model to investigate whether to involve a local agent in incremental innovation in the South.
} 
optimal mode of organization in response to exogenous changes in the market environment in which the multinational subsidiary eventually operates. Section 3 embedds this theory of allocation of authority within multinationals into a simple monopolistic industrial equilibrium model in which domestic firms can serve a foreign market through exports or foreign direct investment. We characterize the equilibrium number of multinationals' subsidiaries serving that market and their equillbrium hierarchical structure. Section 4 then examines how changes in trade costs, fixed costs of FDI and information technologies affect the equilibrium mode of organization of FDI. In section 5 we discuss the implications of local competition and market size effects in the short run with no entry and in the long run with free entry by local firms. In section 6 we finally conclude.

\section{Power Dynamics in the Multinational Firm}

We first start with a simple partial equilibrium model of the choice of firm organization for a multinational serving a foreign market through a subsidiary. This building block will be useful later when we analyze the interaction between the power dynamics of FDI and the market structure in an industry equilibrium model of monopolistic competition.

We consider the situation of a multinational firm contemplating to undertake some foreign direct investment to serve a local market. Production within a subsidiary means running a production project in the host economy. Following Aghion and Tirole (1997), we consider that the multinational has the simplest hierarchical structure consisting of a headquarter (the principal P) located in the country of residence of the multinational, a local manager (the agent A) hired to implement locally the production project in the subsidiary and local labor to run the production plan. There are $m$ potential and a priori identical projects (or ways to produce the good). Payoffs are ex ante unknown to both parties, headquarters and local management. Among the $m$ projects, there are only two viable projects. Both leads to positive recurrent profits $B$ for the firm. One of them though gives to the local manager the possibility to divert part of the income for himself. More precisely, when the first project is implemented, the firm's benefit is the entire profit $B$. On the other hand when the second project is implemented the agent may divert a fraction $\lambda B$ of the benefits. The firm therefore gets only $B(1-\lambda)$ with $0<\lambda<1$. Out of the diverted part $\lambda B$ though, the agent can only receive 
an amount $\lambda \beta B$ with $0<\beta<1$. Hence part of the transferred profit flows are assumed to be dissipated during the diversion process, implying an inefficiency cost of implementing this second type of project.

The values of $B, \lambda$ and $\beta$ are supposed to be known ex ante though the parties do not know ex ante which project yields such payoff. We assume also that, among the $m$ projects, there are some with very high negative payoffs to both parties, implying that choosing randomly a project without being informed is not profitable to both agents who instead prefer to do nothing (project 0 ). This aspect, together with the fact that each uninformed party prefers to rubber-stamp the other informed's party suggestion to do nothing, implies that private information about payoffs gives decision control to the informed party. In this case, the informed party has "real authority" rather than "formal authority". ${ }^{2}$

Parties may acquire information on the payoff structure in the following way. By paying an investment cost $f$, the headquarter of the multinational has access to a centralized information gathering technology which allows him to learn with a given probability $E$ the payoff structure of all projects. It remains uniformed otherwise. Similarly, by dedicating some time effort inside the subsidiary, local management can acquire information on the payoff structure of all projects. More precisely, out of 1 unit of skilled labor time, the manager may dedicate a fraction $h \in[0,1]$ of his time to work for the firm and the rest $1-h$ to work outside at a wage rate $q$. In that case, he learns with probability

$$
e(h)=\bar{e} h, \text { with } 0<\bar{e}<1 .
$$

the structure of projects and remains uninformed with probability $1-e(h)$.

In order to fully focus on the role of allocation of power and delegation in multinational activities, we assume that it is not possible to contract on profit levels $B$ nor on the amount of effort $h$ the manager devotes to produce useful information to the firm. Moreover, both the firm and the agent are risk neutral with respect to income. Given our incomplete contractability assumptions, the multinational cannot therefore incentivize the local manager with monetary rewards. After observing his opportunity cost to work elsewhere, the agent's incentives to gather information on projects will fully have to come from the power he gets

\footnotetext{
${ }^{2}$ As emphasized by Aghion and Tirole 1997, the amount of information acquisition is at the heart of the distinction between "formal" and "real" decision power within firms.
} 
on projects' decisions and therefore on his capacity to choose and implement his "best" project inside the multinational's subsidiary.

Decisions are taken in the following sequence. After paying the investment cost $f$, the multinational (the principal) chooses the organization between nodelegation (P-multinational) or delegation to the subsidiary manager (A-multinational). Then the subsidiary manager (the agent) is hired at a wage $\widetilde{q}$. Then both headquarters and the subsidiary manager collect information about projects' payoffs. The party who does not have decision power suggests a project (or nothing) to the other party. Finally, the party with power rubber stamps the other party's suggestion or selects an alternative project, or decides to do nothing. Hence, the party with formal authority, whenever informed, picks her preferred project. When she remains uninformed ex post, that party rubber-stamps the suggestion of the other party who, whenever informed, has real authority over the project choice and gets his preferred project implemented. When neither party has information on the payoff structure, no project is undertaken by the firm.

Consider first the equilibrium informational effort of the two parties under the two types of organization.

\subsection{A P-multinational Firm}

We start with the case in which the multinational's headquarters keeps formal power (a P-multinational firm). The principal's and the agent's expected payoffs are then

$$
\begin{aligned}
\Pi_{P} & =E B+(1-E) e(h) B(1-\lambda)-\widetilde{q}-f \\
u_{P} & =(1-E) e(h) \beta \lambda B+q(1-h)+\widetilde{q}
\end{aligned}
$$

With probability $E$, the multinational top management (the principal) becomes fully informed about her payoffs and picks her preferred project with payoff $B$. With probability $1-E$, the multinational headquarter remains uninformed about payoffs. The subsidiary manager decides how to allocate her time $h$ (whether to work for the firm or to shirk and work for himself). She learns with probability $e(h)$ the payoff structure. In that case, she suggests to the uninformed headquarters her best project (which is accepted). Owners/headquarters receive 
then the payoff $B(1-\lambda)$ while the subsidiary manager gets her diverted benefit $\beta \lambda B$.

The first order conditions for the subsidiary manager are

$$
\begin{aligned}
& h_{P}^{*}=1 \text { and } e=\bar{e} \text { if } q<\beta \lambda \bar{e} B(1-E) \\
& h_{P}^{*}=0 \text { and } e=0 \text { if } q>\beta \lambda \bar{e} B(1-E) \\
& h_{P}^{*} \in[0,1] \text { and } e \in[0, \bar{e}] \text { if } q=\beta \lambda \bar{e} B(1-E)
\end{aligned}
$$

The conditions highlight the trade off between the headquarter's control and the subsidiary manager's initiative. The better the headquarter's infomation technology (larger $E$ ), the lower the incentive for the subsidiary manager to spend efforts to gather information on implementable projects. Control thus comes with the cost of loosing the agent's initiative. In turn, the larger the profits $\beta \lambda B$ the subsidiary manager can divert from a project and the lower her time opportunity costs $q$, the larger the effort of the local manager to gather information for the firm.

Given that the agent's reservation income is his opportunity cost of labor $q$, $\widetilde{q}$ should be fixed such that $u_{A}=q$. The firm's equilibrium payoff under a $\mathrm{P}$ organization is then given by:

$$
\Pi_{P}^{*}=E B+(1-E) e\left(h_{P}^{*}\right) B(1-\lambda)+(1-E) e\left(h_{P}^{*}\right) \beta \lambda B-q h_{P}^{*}-f
$$

or more explicitely, posing $K=1-\lambda(1-\beta)$ and

$$
B_{P}(E)=\frac{1}{\beta \lambda \bar{e}(1-E)}
$$

$$
\begin{aligned}
\Pi_{P}^{*} & =E B+(1-E) \bar{e} B K-q-f \text { if } B_{P}(E)<B / q \\
& =E B-f \quad \text { if } \quad B_{P}(E)>B / q \\
& =E B+[(1-E) B \bar{e} K-q] h_{P}^{*}-f \quad \text { with } h_{P}^{*} \in[0,1] \text { if } B_{P}(E)=B / q
\end{aligned}
$$




\subsection{An A-multinational Firm}

Consider now the case where the multinational has delegated decision control to the subsidiary manager and thus the agent has formal authority. Now, headquarters are prevented from overruling the agent's decision when both have acquired information. The two parties' expected payoffs are then

$$
\begin{aligned}
\Pi_{A} & =e(h) B(1-\lambda)+(1-e(h)) E B-f-\widetilde{q} \\
u_{A} & =e(h) \beta \lambda B+q(1-h)+\widetilde{q}
\end{aligned}
$$

Now the agent chooses his preferred project when informed. When the principal is informed and the agent is uninformed, the principal suggests her preferred project, which is then implemented by the agent.

The analysis is similar to the one of the P-multinational. We get the following characterization of the equilibrium effort level of the local manager:

$$
\begin{aligned}
& h_{A}^{*}=1 \text { and } e=\bar{e} \text { if } q<\beta \lambda \bar{e} B \\
& h_{A}^{*}=0 \text { and } e=0 \text { if } q>\beta \lambda \bar{e} B \\
& h_{A}^{*} \in[0,1] \text { and } e \in[0, \bar{e}] \text { if } q=\beta \lambda \bar{e} B
\end{aligned}
$$

Again, given that the agent's reservation income is his opportunity cost of labor $q, \widetilde{q}$ should be fixed such that $v_{A}=q$ and the firm's equilibrium payoff under a A organization is immediatly given by:

$$
\begin{aligned}
\Pi_{A}^{*} & =E B+(K-E) \bar{e} B-q-f \quad \text { if } \quad B_{A}<B / q \\
& =E B-f \quad \text { if } \quad B_{A}>B / q \\
& =E B+[(K-E) B \bar{e}-q] h_{A}^{*}-f \quad \text { with } h_{A}^{*} \in[0,1] \text { if } \quad B_{A}=B / q
\end{aligned}
$$

with

$$
B_{A}=\frac{1}{\beta \lambda \bar{e}}
$$

defining the profit threshold below which the local manager does not put any effort in the firm.

As $\frac{1}{\beta \lambda}<\frac{1}{\beta \lambda(1-E)}$, then $B_{A}<B_{P}(E)$ and $h_{A}^{*} \geq h_{p}^{*}$. The agent A's initiative is triggered at a lower profit level $B / q$ under the A-organization than under the Porganization. The reason is that under the A-firm the agent has formal authority and therefore has better effort incentives than when the principal has formal 
authority. Hence, it requires a smaller stake to motivate the agent to undertake initiative under the A-firm than under the P-firm. Consequently, the threshold level of profits of the principal at which the agent's effort is stimulated is lower under the A-firm as compared to the P-firm.

Note finally that the multinational's payoff is the same under the two organizations when the agent does not provide any effort level (ie. when $h=0$ ). In that case the multinational's organization is equivalent to a subsidiary with a dummy local manager. Hence, we define this as a multinational O-organization (or O-multinational).

\subsection{Optimal Multinational Organization}

The derivation of the optimal organizational form of the firm can be obtained by comparing (2.2) to (2.3) at different profit levels of the multinational. Three cases can then be distinguished.

\section{Case 1: $B / q \leq B_{A}$ (low profits)}

The utility levels of headquarters (the principal) under the two forms of organization are simply $\Pi_{P}^{*}=\Pi_{A}^{*}=E B-f=\Pi_{O}^{*}$

Given that $h_{A}^{*}=h_{P}^{*}=0$, the equilibrium organization is an O-multinational. At this profit level there is no trade-off between headquarters' control and the subsidiary manager's initiative. When $B / q$ is low, the subsidiary manager's stakes to engage in the firm are so low that even when power is delegated to her (ie.in an A-multinational), the agent has no incentive to put any effort into the firm. Both organizations give rise to an O-multinational.

Case 2: $B_{A}<B / q \leq B_{P}(E)$ (intermediate profits)

At this profit level, the P-multinational kills the agent's effort and $h_{P}^{*}=0$, while he exerts maximal effort $h_{A}^{*}=1$ under the A-multinational. Thus, the multinational's expected payoff under the two organizations are given respectively by:

$$
\Pi_{P}^{*}=\Pi_{O}^{*}=E B-f \text { and } \Pi_{A}^{*}=E B+(K-E) \bar{e} B-q-f
$$


In such a case, $\Pi_{O}^{*}<\Pi_{A}^{*}$ if and only if

$$
\frac{B}{q}>\frac{1}{(K-E) \bar{e}}
$$

$\frac{1}{(K-E) \bar{e}}$ is the critical profit level at which headquarters are indifferent between centralization without initiative (a O-multinational) and the delegated Amultinational with full initiative. Above the profit level $B / q$ the principal prefers to delegate power to the subsidiary manager at the cost of loosing control inside the multinational corporation.

The preceding discussion can be summarized in a more compact way. Denote

$$
\bar{B}(E)=\operatorname{Max}\left[\frac{1}{\lambda \beta \bar{e}} ; \frac{1}{(K-E) \bar{e}}\right]
$$

Then at intermediate profits the optimal firm organization switches in the following way:. i) $B / q<\bar{B}(E)$ the O-multinational with no agent's effort dominates the A-multinational. ii) $B / q>\bar{B}(E)$ the A-multinational dominates.

Case 3: $B_{P}(E)<B / q$ (high profits)

In this case we have to compare

$$
\Pi_{P}^{*}=E B+(1-E) \bar{e} B K-q-f \quad \text { to } \Pi_{A}^{*}=E B+(K-E) \bar{e} B-q-f
$$

As $(1-E) \bar{e} B K>(K-E) \bar{e} B$ as $K=1-\lambda(1-\beta)<1$ and therefore $\Pi_{P}^{*}>\Pi_{A}^{*}$ headquarters prefers the $\mathrm{P}$-multinational organization. At this profit level there is again no trade-off between control and initiative. Both types of organizations $\mathrm{P}$ and A stimulate fully the agent's initiatives. As the $\mathrm{P}$ multinational gives control to the heaquarter, it is preferred by the multinational.

We summarize the preceding discussion in proposition 1, stating the optimal organization of the multinational firm as a function of the multinational 's recurrent payoff $B$ :.

Proposition 2.1. Let $E_{\max }=(1-\lambda) /(1-\lambda \beta)$ 
i) When $E \geq E_{\max }$, the delegated A-multinational is never optimal. For $B / q<B_{P}(E)$ the equilibrium organization is the O-multinational organization. For $B / q>B_{P}(E)$, the equilibrium organization is the $P$-multinational with full initiative (ie. with $h_{P}^{*}=1$ ) If $B / q=B_{P}(E)$, then the optimal organization is a $P$-multinational with some interior initiative $h_{P}^{*} \in[0,1]$.

ii) When $E \in] 1-\lambda, E_{\max }[$, we have the following pattern: iia) For $B / q<\bar{B}(E)$, the equilibrium organization is the O-multinational. iib) For $B / q=\bar{B}(E)$, the equilibrium organization is the O-multinational or a $A$-multinational with full initiative $h_{A}^{*}=1$. iic) For $\bar{B}(E)<B / q<B_{P}(E)$, the equilibrium organization is the A-multinational with full initiative $h_{A}^{*}=1$. iid) For $B_{P}(E)=B / q$, the equilibrium organization is the $P$-multinational with some interior initiative $h_{P}^{*} \in$ $\left[\underline{h}_{P}, 1\right]$. iie) For $. B_{P}(E)<B / q$, the equilibrium organization is the P-multinational with full initiative $h_{P}^{*}=1$.

iii) When $E \leq 1-\lambda$, we have the following pattern: iiia) For $B / q<\bar{B}(E)$, the equilibrium organization is the O-multinational. iiib) For $B / q=\bar{B}(E)$, the equilibrium organization is a $A$-multinational with some interior initiative $h_{A}^{*} \in$ $[0,1]$. iiic) For $\bar{B}(E)<B / q<B_{P}(E)$, the equilibrium organization is the $A$ multinational with full initiative $h_{A}^{*}=1$. iiid) For $\cdot B_{P}(E)=B / q$, the equilibrium organization is the $P$-multinational.with some interior initiative $h_{P}^{*} \in\left[\underline{h}_{P}, 1\right]$. iiie) For $. B_{P}(E)<B / q$, the equilibrium organization is the $P$-multinational with full initiative $h_{P}^{*}=1$.

The proposition is illustrated in Figures 1a), 1b) and 1c) plotting the shape of the principal's profit function as a function of $B / q$. The three curves $\Pi_{O}(B / q)=$ $E B / q ; \Pi_{A}(B / q)=E B / q+(K-E) \bar{e} B / q-1$ and $\Pi_{E}(B / q)=E B / q+(1-$ $E) \bar{e} K B / q-1$ are depicted.

The three cases are illustrated. The first one (ie. Figure 1a) corresponds to $B_{P}(E)<1 /(K-E) \bar{e}$ or equivalently $E \geq E_{\max }$. The profit function under the O-multinational organization $\Pi_{O}(B / q)$ crosses the profit function of the Amultinational organization $\Pi_{A}(B / q)$ at some point above $B_{P}(E)$. In that case, the $A$ multinational is always dominated and we have the situation depicted by i). Note that at $B / q=B_{P}(E)$, there is a upward jump of the profit function from $\Pi_{O}(B / q)$ to $\Pi_{E}(B / q)$. As the agent is indifferent at this point between doing nothing or investing in the organization, the vertical part then correponds to interior values of initiatives of the agent $h_{P}^{*} \in\left[\underline{h}_{P}, 1\right]$ and is described by the segment $P M$ in figure 1a). 
The second case is represented in Figure 1b) and corresponds to $1 / \lambda \beta \bar{e}<$ $1 /(K-E) \bar{e}<B_{P}(E)$ with $\bar{B}(E)=1 /(K-E) \bar{e}$. This happens when $\left.E \in\right] 1-$ $\lambda, E_{\max }\left[\right.$. In such a case $\Pi_{O}(B / q)$ crosses $\Pi_{A}(B / q)$ at point $\bar{B}(E)$ and we have the situation depicted by ii). Note again that at $B_{P}(E)=B / q$, there is an upward discontinuous jump as the profit function under the P-multinational with full initiative with $\Pi_{P}(B / q)$ is above the profit function of the A-multinational with full initiative $\Pi_{A}(B / q)$. Now at $B_{P}(E)=B / q$, making the agent initiative $h_{P}^{*}$ varying from 0 to 1, one can see that the profit level under the P-multinational moves from $\Pi_{O}\left(B_{P}(E)\right)<\Pi_{A}\left(B_{P}(E)\right)$ (ie. point X) to $\Pi_{P}\left(B_{P}(E)\right)>\Pi_{A}\left(B_{P}(E)\right)$ (ie. point $\mathrm{Y})$. Thus, by continuity, there is a unique value $\underline{h}_{P}$ such that for $h_{P}^{*} \in\left[\underline{h}_{P}, 1\right]$, $E B / q+[(1-E) \bar{e} K B / q-1] h_{P}^{*}>\Pi_{A}\left(B_{P}(E)\right)$. Hence, a P-multinational with any partial initiative $h_{P}^{*} \in\left[\underline{h}_{P}, 1\right]$ will dominate the A-multinational with full initiative and be an optimal organizational form and is described again by segment $P M$ in Figure 1b)

Finally the last case is depicted in Figure 1c) where $1 /(K-E) \bar{e}<1 / \lambda \beta \bar{e}<$ $B_{P}(E)$. It corresponds to the situation $E \leq 1-\lambda$ and $\bar{B}(E)=1 / \lambda \beta \bar{e}$. Now there is also an upward jump at point $B / q=\bar{B}(E)$, as the $\Pi_{O}(B / q)$ curve crosses $\Pi_{A}(B / q)$ at $1 /(K-E) \bar{e}<1 / \lambda \beta \bar{e}=\bar{B}(E)$. Doing the same line of reasoning as before the vertical part at that point $B / q=\bar{B}(E)$ corresponds to a optimal A-multinational with any partial agent's initiative $h_{A}^{*} \in[0,1]$.(ie. region $A M$ in Figure 1c)

We can also illustrate proposition 2.1 in Figure 2 in the plane $(B / q, E)$ of real profits in terms of managerial labor and the technology of information of the multinational headquarter. The curve $B_{P}$ shows the threshold $B_{P}(E)$ below which the agent's initiative inside a $\mathrm{P}$-multinational organization is crowded out. It is an upward sloping curve as more information $E$, and therefore control by the headquarter, reduces the incentives of the agents to take intiative. The curve $\bar{B}$ reflects as well the function $\bar{B}(E)$. It is consists of a vertical part $B_{A}$ and an upward sloping part $\overline{B B}$. The vertical part corresponds to the threshold of profits above which the agent starts to take initiative in the delegated structure (ie. $B / q==1 / \lambda \beta \bar{e}$ ). The part $\overline{B B}$ defines the threshold value of profits at which the principal is indifferent between stimulating initiative inside the A-multinational and losing decision control in the O-multinational (ie. $B / q=1 /(K-E) \bar{e})$. An increase in $E$ tends to favor control at the expense of initiatives. In order to maintain indifference between the two organization forms, the agent's stakes (proportional to the firm's profit) have to increase to restablish the balance between control and initiatives 
inside the firm. Hence the positive slope of $\bar{B}(E)$. It should be clear that the $\overline{B B}$ curve crosses the $B_{P}$ at point $E_{\max }<1$. The different equilibrium organizational forms of the multinational firm are illustrated in Figure 2.

When the information technology of the multinational headquarters is very efficient (ie. $E \geq E_{\max }$ ), decision power is never delegated to local management inside the firm's subsidiary. Under centralized control, the hierarchical P-multinational will matter only as long as the agent has enough stakes ( ie. $B / q$ above the $B_{P}$ curve) to undertake initiative inside that structure. Otherwise an O-multinational will prevail without subsidiary management initiative.

When the firm's headquarter does not have access to good quality information (ie. $E<E_{\max }$ ), then delegation can prove to be optimal, though this will imply diversion of rents by local management. In that case, the multinational's organization matters for incentives inside the firm at intermediate levels of profits only. At low and high profit levels there is no trade-off between control and initiative. At low profit levels (ie. for $B / q$ below the $\bar{B}$ curve), the stakes for diversion by the subsidiary manager are small and she cares little. Therefore, there is no agent's initiative in any organizational form and the O-multinational emerges naturally. At high profit levels (ie. $B / q$ above the $B_{P}$ curve), the agent's stakes are so large that she intervenes even under the centralized $\mathrm{P}$-multinational leading to maximum effort by the agent in both types of organizations (A and P). Since P has more control under the P-firm compared to the A-firm, the principal (the firm's headquarter) prefers the P-firm. At intermediate levels of profits there is a tradeoff between control and initiative. When the profit level $B$ keeps increasing in that intermediate range, the gain emanating from the agent initiative overcomes the loss of control of the principal and the O-firm with no incentives for the agent becomes dominated by the delegated A-firm (ie. in the region for $B / q$ in between above the $\bar{B}$ curve and the $B_{P}$ curve).

In the remaining paper we will limit ourselves to the case where:

$$
\text { Assumption A1: } E \in] 1-\lambda, E_{\max }=(1-\lambda) /(1-\lambda \beta)[
$$

that is the case described by ii) in proposition 1 . This corresponds to the case of intermediate efficiency of the information technology of the multinational's headquarter such that power delegation to the subsidiary manager (the A-multinational) with full initiative can emerge. 


\section{Industry Equilibrium}

In this section we endogenize the multinational 's profit $B$ as well as the decision to access a local market by FDI or by exports, for a given international market structure of the industry. This will allow us to analyze the interaction between the organization of multinational firms, exports, trade frictions and market competition. In order to do this, we embedd our previous model of power inside the firm of the previous section in an equilibrium framework with monopolistic competition. We consider a particular local market characterized by $L$ consumers whose preferences are defined over a continuum of differentiated varieties indexed by $i \in[0, N]$ and an homogenous good 0 chosen as the numeraire.

$$
U=x_{0}+\left[\int_{0}^{N} x(i)^{\frac{\sigma-1}{\sigma}} d i\right]^{\frac{\sigma}{\sigma-1}}
$$

The numeraire good 0 is produced with constant returns to scale (one unit of good 0 requires one unit of unskilled labor) and under perfect competitive conditions. The unskilled labor wage $w$ is therefore pinned down to 1. Each variety of the differentiated good is produced under monopolistically competitive conditions. There are two types of firms potentially operating in the sector: local firms in number $n$ and foreign firms in total number $n^{*}$. Foreign firms can access the local market in two ways: exports or FDI. Local firms and (eventually) subsidiaries of foreign multinationals can produce a given variety $i$ with constant marginal $\operatorname{cost} c$, while foreign exports are produced outside at the constant foreign marginal cost $c^{*}$ and are subjects to iceberg trade costs $\tau>1$.

We introduce then a crucial difference between the export strategy and the FDI strategy to serve the local market. We assume that access to the market through exports does not need relevation of new information and that production is operated under the production plan with foreign cost $c^{*}$ and subject to the trade friction $\tau$

To serve however the local market through FDI, we assume that a foreign firm needs to acquire information on how to implement local production. More precisely, the firm has to undertake a profitable production project which is a way to run the firm's production with a constant marginal cost technology. We 
embed then our previous model of power inside the firm by assuming that there are ex ante $m$ alternative ways to produce the good. Thus, before starting to produce the firm needs to get informed about the cost parameters of the various local ways of producing. By paying a fixed cost $f$, headquarters have access to an information technology which discovers with probability $E$ all local production projects payoffs. The firm may also hire a local skilled agent (subsidiary manager) who can spend some time effort $h \in[0,1]$ to get the relevant information with probability $e(h)$ as described in (2.1). As before we assume that out of all the possibilities, only two projects are worth doing from the point of view of the two parties.These two projects implement production with the local marginal production $\operatorname{cost} c$. As before though, one of the projects gives to the local manager the possibility to divert part of the income for himself. More precisely under that project, if the firm's entire recurrent benefit is $B$, the agent may divert a fraction of the benefits $\lambda B$, and receives actually the smaller amount $\lambda \beta B$ with $0<\beta<1$. When no information is revealed, we assume that a foreign subsidiary prefers not to produce rather than undertake any randomized project locally.

\subsection{Monopolistic competition and product market}

Given Dixit-Stiglitz preferences, the demand of each firm $i$ is of the form

$$
x(i)=\frac{L}{\int_{0}^{N} p(j)^{1-\sigma} d j} p(i)^{-\sigma}
$$

where $p(i)$ is the price of good $i$ and $N$ the total number of firms operating in the market

For a product with marginal cost of production $c(i)$, monopolistic profit maximization provides the standard mark-up relationship

$$
p(i)=\frac{\sigma}{\sigma-1} c(i)
$$

and recurrent profit levels can be written as

$$
\pi(i)=\frac{L}{\int_{0}^{n} p(j)^{1-\sigma} d j}\left(\frac{\sigma}{\sigma-1}\right)^{1-\sigma} \frac{[c(i)]^{1-\sigma}}{\sigma}
$$


Given the symmetry of the problem, the recurrent profit of a local firm and a multinational subsidiary is simply written as

$$
\pi_{I}=\frac{L}{\sigma} \frac{c^{1-\sigma}}{\left(n+n_{I}\right) c^{1-\sigma}+n_{X}\left(c^{*} \tau\right)^{1-\sigma}}
$$

while the profit from exports writes as:

$$
\pi_{X}=\frac{L}{\sigma} \frac{\left(c^{*} \tau\right)^{1-\sigma}}{\left(n+n_{I}\right) c^{1-\sigma}+n_{X}\left(c^{*} \tau\right)^{1-\sigma}}
$$

where $n_{I}$ is the number of operating foreign subsidiaries inside the country and $n_{X}$ is the number of foreign exporters. Using the usual "freeness" of trade index $\varphi=\left(c / c^{*} \tau\right)^{\sigma-1}$ which is decreasing with trade friction $\tau$ and assumed to be less than 1 (ie $c \leq c^{*}$ ), we get the following profits

$$
\pi_{I}=\frac{L}{\sigma} \frac{1}{n+n_{I}+n_{X} \varphi} \quad \text { and } \quad \pi_{X}=\frac{L}{\sigma} \frac{\varphi}{n+n_{I}+n_{X} \varphi}
$$

Taking this into account we can rewrite the principal's profit when her or the agent's best project is implemented, respectively, as in the firm equilibrium framework of section 2 with the profit level of the principal $B=\pi_{I}$.

\subsection{Multinational Equilibrium and the Choice between Exports and FDI}

We are now going to characterize the nature of the equilibrium organizational FDI structures and the choice for a foreign firm between serving the local market through exports or through the establishment of a foreign subsidiary. Generally, FDI will be preferred by a foreign firm if and only if

$$
\pi_{X} \leq W_{I}-f
$$

where $W_{I}$ is the optimal expected recurrent profit of a foreign subsidiary in the local market and $f$ is the set-up cost of that subsidiary. Depending on the optimal allocation of power inside a multinational firm, different equilibrium regimes are possible. To analyze them we introduce some notations. Denote $\nu_{O}(E)=E$; 
$\nu_{A}(E)=E+(K-E) \bar{e}$ and $\nu_{P}(E)=E+(1-E) \bar{e} K$ and $Q_{O}(E)=E ; Q_{P}(E)=$ $Q_{A}(E)=E+(1-E) \bar{e}$, and $Q(E, h)=E+(1-E) \bar{e} h$ for $h \in[0,1]$.

\section{i) P-multinational Equilibrium with Full Initiative}

In that case,

$$
W_{I}=\nu_{P}(E) \pi_{I}-q
$$

Noting that $\pi_{X}=\varphi \pi_{I}$, the conditions for positive FDI in this regime is

$$
\frac{L}{\sigma} \frac{\varphi}{n+n_{I}+n_{X} \varphi}=\frac{L}{\sigma} \frac{\nu_{P}(E)}{n+n_{I}+n_{X} \varphi}-q-f \gtrsim 0
$$

and

$$
B=\frac{L}{\sigma} \frac{1}{n+n_{I}+n_{X} \varphi}>q B_{P}(E)
$$

This can be rewritten as

$$
\frac{L}{\sigma} \frac{\nu_{P}(E)-\varphi}{n+n_{I}+n_{X} \varphi}-q=f \text { and } n_{I} \geq 0
$$

Now if we denote by $n_{I}^{0}$ the number of foreign firms choosing to access the local market through FDI, only the fraction $Q_{P}(E)$ will successfully implement a production project. Therefore using the law of large numbers, we have the relationship

$$
n_{X}+n_{I}^{0}=n^{*} \text { and } n_{I}=n_{I}^{0} Q_{P}(E)
$$

which provides the following conditions for this FDI regime

$$
\frac{L}{\sigma} \frac{\nu_{P}(E)-\varphi}{n+n^{*} \varphi+n_{I}\left(1-\frac{\varphi}{Q_{P}(E)}\right)}-q=f \text { and } n_{I} \geq 0
$$

and

$$
\frac{L}{\sigma} \frac{1}{n+n^{*} \varphi+n_{I}\left(1-\frac{\varphi}{Q_{P}(E)}\right)}>q B_{P}(E)
$$

Rearranging (3.3) determines the equilibrium number of multinational firms

$$
n_{I}^{P}=\frac{1}{1-\frac{\varphi}{Q_{P}(E)}}\left[\frac{\nu_{P}(E)-\varphi}{\left[1+\frac{f}{q}\right]} \frac{L}{\sigma q}-\left(n+n^{*} \varphi\right)\right]
$$


Condition (3.4) is given as

$$
\frac{1+f / q}{B_{P}(E)}>\nu_{P}(E)-\varphi
$$

Also the condition for positive FDI is given as

$$
n_{I} \geq 0 \Leftrightarrow \varphi \leq \varphi_{0}^{P}\left(\frac{f}{q}, E, n, n^{*}, L\right)=\frac{\frac{L}{\sigma q} \nu_{P}(E)-\left[1+\frac{f}{q}\right] n}{\frac{L}{\sigma q}+\left[1+\frac{f}{q}\right] n^{*}}<Q_{P}(E)
$$

while condition (3.5) becomes

$$
\varphi>\widetilde{\varphi}_{P}\left(E, \frac{f}{q}\right)=\nu_{P}(E)-\frac{\left[1+\frac{f}{q}\right]}{B_{P}(E)}
$$

It is a simple matter to see that the curve $\varphi_{0}^{P}\left(\frac{f}{q}, E, n, n^{*}, L\right)$ is decreasing in $f / q$. As well, the curve $\widetilde{\varphi}_{P}\left(E, \frac{f}{q}\right)$ is linear decreasing in $f / q$ and $\varphi_{0}^{P}\left(-1, E, n, n^{*}, L\right)=$ $\widetilde{\varphi}_{P}(E,-1)$. Therefore a necessary and sufficient condition for the existence of such a regime is that there exists some $\varphi$ and $\frac{f}{q}>0$ such that :

$$
\widetilde{\varphi}_{P}\left(E, \frac{f}{q}\right)<\varphi<\varphi_{0}^{P}\left(\frac{f}{q}, E, n, n^{*}, L\right)
$$

This condition defines a non empty set of values of $\varphi$ when the horizontal intercept at the origin of the function $\varphi_{0}^{P}\left(\frac{f}{q}, E, n, n^{*}, L\right)$ (ie. $\left.\frac{L}{\sigma q n} \nu_{P}(E)-1\right)$ is larger than the horizontal intercept at the origin of the function $\widetilde{\varphi}_{P}\left(E, \frac{f}{q}\right)\left(\right.$ ie. $\left.\nu_{P}(E) B_{P}(E)-1\right)$ or the condition ${ }^{3}$ :

$$
n<\frac{L}{\sigma q B_{P}(E)}
$$

We may then summarize the preceding discussion in the following proposition:

\footnotetext{
${ }^{3}$ Given the convexity of the function $\varphi_{0}^{P}\left(\frac{f}{q}, E, n, n^{*}, L\right)$ in $f / q$, it is also easy to see that when $n<\frac{L}{\sigma q B_{P}(E)}-n^{*} \nu_{P}(E)$, then $\varphi_{0}^{P}\left(\frac{f}{q}, E, n, n^{*}, L\right)>\widetilde{\varphi}_{P}\left(E, \frac{f}{q}\right)$ for all $\frac{f}{q}$.
} 
Proposition 3.1. i) When $n<\frac{L}{\sigma q B_{P}(E)}$, there exists a $P$-multinational equilibrium with full initiative if and only if

$$
\widetilde{\varphi}_{P}\left(E, \frac{f}{q}\right)<\varphi<\varphi_{0}^{P}\left(\frac{f}{q}, E, n, n^{*}, L\right)
$$

and the equilibrium number of subsidiaries is given by

$$
n_{I}^{P}=\frac{1}{1-\frac{\varphi}{Q_{P}(E)}}\left[\frac{\nu_{P}(E)-\varphi}{\left[1+\frac{f}{q}\right]} \frac{L}{\sigma q}-\left(n+n^{*} \varphi\right)\right]>0
$$

ii) When $n>\frac{L}{\sigma q B_{P}(E)}$, there does not exist a $P$-multinational equilibrium with full initiative.

ii) P-multinational Equilibrium with Partial Initiative $h_{P}^{*} \in\left[\underline{h}_{P}, 1[\right.$.

In this regime, we have :

$$
\frac{L}{\sigma} \frac{1}{n+n^{*} \varphi+n_{I}\left(1-\frac{\varphi}{Q_{P}(E, h)}\right)}=q B_{P}(E)
$$

Denoting $\nu_{P}(E, h)=E+(1-E) \bar{e} h K$ for $h \in[0,1]$, the arbitrage condition between exports and FDI is given by

$$
\frac{L}{\sigma} \frac{\varphi}{n+n^{*} \varphi+n_{I}\left(1-\frac{\varphi}{Q_{P}(E, h)}\right)}=\frac{L}{\sigma} \frac{\nu_{P}(E, h)}{n+n^{*} \varphi+n_{I}\left(1-\frac{\varphi}{Q_{P}(E, h)}\right)}-q h-f
$$

The P-multinational firm with interior initiative dominates the A-multinational firm with full initiative. This translates into the following condition:

$$
\frac{L}{\sigma} \frac{\nu_{P}(E, h)}{n+n^{*} \varphi+n_{I}\left(1-\frac{\varphi}{Q_{P}(E, h)}\right)}-q h \geq \frac{L}{\sigma} \frac{\nu_{A}(E)}{n+n^{*} \varphi+n_{I}\left(1-\frac{\varphi}{Q_{P}(E, h)}\right)}-q
$$

The first two conditions (3.9) and (3.10) give the equilibrium value of $h_{P}$ :

$$
B_{P}(E)\left[\nu_{P}\left(E, h_{P}\right)-\varphi\right]-h_{P}=\frac{f}{q}
$$


It is shown in the appendix that a necessary and sufficient condition for the existence of such a regime with positive FDI is that

$$
n<\frac{1}{B_{P}(E)} \frac{L}{\sigma q}
$$

and that :

$$
\widetilde{\varphi}_{m}\left(E, \frac{f}{q}\right)<\varphi<\operatorname{Min}\left[\widetilde{\varphi}_{m}^{0}(E) ; \widetilde{\varphi}_{P}\left(E, \frac{f}{q}\right)\right]
$$

where

$$
\widetilde{\varphi}_{m}\left(E, \frac{f}{q}\right)=\nu_{A}(E)-\left[1+\frac{f}{q}\right] \frac{1}{B_{P}(E)} \text { and } \widetilde{\varphi}_{m}^{0}(E)=\frac{\frac{1}{B_{P}(E)} \frac{L}{\sigma q}-n}{n^{*}}
$$

Moreover the equilibrium number of multinationals in that regime is then simply given by :

$$
n_{I}^{m}=\frac{1}{1-\frac{\varphi}{Q_{P}\left(E, h_{P}\right)}}\left[\frac{1}{B_{P}(E)} \frac{L}{\sigma q}-\left(n+n^{*} \varphi\right)\right]
$$

We get then the following proposition:

Proposition 3.2. i) When $n<\frac{L}{\sigma q B_{P}(E)}$, there exists a FDI regime with $P$ multinational firms with partial initiative $h_{P}<1$ if and only if

$$
\widetilde{\varphi}_{m}\left(E, \frac{f}{q}\right)<\varphi<\operatorname{Min}\left[\widetilde{\varphi}_{m}^{0}(E) ; \widetilde{\varphi}_{P}\left(E, \frac{f}{q}\right)\right]
$$

and the equilibrium number of subsidiaries is given by:

$$
n_{I}^{m}=\frac{1}{1-\frac{\varphi}{Q_{P}\left(E, h_{P}\right)}}\left[\frac{1}{B_{P}(E)} \frac{L}{\sigma q}-\left(n+n^{*} \varphi\right)\right]>0
$$

ii) When $n>\frac{L}{\sigma q B_{P}(E)}$, there does not exist a $P$-multinational equilibirum with partial initiative. 


\section{iii) A-multinational Equilibrium with Full Initiative}

The conditions for such a regime are

$$
n_{I}=\frac{1}{1-\frac{\varphi}{Q_{A}(E)}}\left[\frac{\nu_{A}(E)-\varphi}{\left[1+\frac{f}{q}\right]} \frac{L}{\sigma q}-\left(n+n^{*} \varphi\right)\right]>0
$$

and

$$
q \bar{B}(E)<\frac{L}{\sigma} \frac{1}{n+n^{*} \varphi+n_{I}\left(1-\frac{\varphi}{Q_{A}(E)}\right)}<q B_{P}(E)
$$

which can be rearranged to

$$
\varphi<\widetilde{\varphi}_{m}\left(E, \frac{f}{q}\right)=\nu_{A}(E)-\left[1+\frac{f}{q}\right] \frac{1}{B_{P}(E)}
$$

and

$$
\varphi>\widetilde{\varphi}_{A}\left(E, \frac{f}{q}\right)=\nu_{A}(E)-\left[1+\frac{f}{q}\right] \frac{1}{\bar{B}(E)}
$$

Finally, the condition for positive FDI in such a regime is

$$
n_{I} \geq 0 \Leftrightarrow \varphi \leq \varphi_{0}^{A}\left(\frac{f}{q}, E, n, n^{*}, L\right)=\frac{\frac{L}{\sigma q} \nu_{A}(E)-\left[1+\frac{f}{q}\right] n}{\frac{L}{\sigma q}+\left[1+\frac{f}{q}\right] n^{*}}<Q_{A}(E)
$$

Hence, the necessary and sufficient conditions for the existence of such a regime is that for some $\varphi$ and $\frac{f}{q}>0$

$$
\widetilde{\varphi}_{A}\left(E, \frac{f}{q}\right)<\varphi<\operatorname{Min}\left[\varphi_{0}^{A}\left(\frac{f}{q}, E, n, n^{*}, L\right), \widetilde{\varphi}_{m}\left(E, \frac{f}{q}\right)\right]
$$

Again, this condition defines a non empty set of values of $\varphi$ when the horizontal intercept at the origin of the function $\varphi_{0}^{A}\left(\frac{f}{q}, E, n, n^{*}, L\right)$ (ie. $\left.\frac{L}{\sigma q n} \nu_{A}(E)-1\right)$ is larger than the horizontal intercept at the origin of the function $\widetilde{\varphi}_{A}\left(E, \frac{f}{q}\right)$ (ie. $\left.\nu_{A}(E) \bar{B}(E)-1\right)$ or the condition ${ }^{4}$ :

$$
\nu_{A}(E) \bar{B}(E)<\frac{L}{\sigma q n} \nu_{A}(E)
$$

\footnotetext{
${ }^{4}$ It can be easily shown as well that the value of $\varphi$ at which eventually $\varphi_{0}^{A}\left(\frac{f}{q}, E, n, n^{*}, L\right)$ is equal to $\widetilde{\varphi}_{m}\left(E, \frac{f}{q}\right)$ is also $\widetilde{\varphi}_{m}^{0}(E)$ and that the vaue $\varphi$ at which eventually $\varphi_{0}^{A}\left(\frac{f}{q}, E, n, n^{*}, L\right)$ is equal to $\widetilde{\varphi}_{A}\left(E, \frac{f}{q}\right)$ is $\widetilde{\varphi}_{O}(E)=\frac{\frac{1}{\bar{B}(E)} \frac{L}{\sigma q}-n}{n^{*}}$
} 
which gives

$$
n<\frac{L}{\sigma q \bar{B}(E)}
$$

Hence the proposition

Proposition 3.3. i) When $n<\frac{L}{\sigma q \bar{B}(E)}$, there exists an A-multinational equilibrium with full initiative if and only if

$$
\widetilde{\varphi}_{A}\left(E, \frac{f}{q}\right)<\varphi<\operatorname{Min}\left[\varphi_{0}^{A}\left(\frac{f}{q}, E, n, n^{*}, L\right), \widetilde{\varphi}_{m}\left(E, \frac{f}{q}\right)\right]
$$

and the equilibrium number of subsidiaries is given by:

$$
n_{I}^{A}=\frac{1}{1-\frac{\varphi}{Q_{A}(E)}}\left[\frac{\nu_{A}(E)-\varphi}{\left[1+\frac{f}{q}\right]} \frac{L}{\sigma q}-\left(n+n^{*} \varphi\right)\right]>0
$$

ii) When $n>\frac{L}{\sigma q \bar{B}(E)}$, there cannot exist an A-multinational equilibrium with full initiative.

\section{iv) O-multinational Equilibrium}

Finally, the existence conditions for such a regime are:

$$
n_{I}=\frac{1}{1-\frac{\varphi}{Q_{O}(E)}}\left[\frac{\nu_{O}(E)-\varphi}{f} \frac{L}{\sigma}-\left(n+n^{*} \varphi\right)\right]>0
$$

with

$$
\frac{L}{\sigma} \frac{1}{n+n^{*} \varphi+n_{I}\left(1-\frac{\varphi}{Q_{O}(E)}\right)}<q \bar{B}(E)
$$

Substituting and rearranging (3.14) gives then the following conditions on the "freeness" of trade: for positive FDI

$$
\varphi \leq \varphi_{0}^{O}\left(f, E, n, n^{*}, L\right)=\frac{\frac{L}{\sigma} \nu_{O}(E)-f n}{\frac{L}{\sigma}+f n^{*}}
$$


while condition (3.15) can be rewritten as:

$$
\varphi<\nu_{O}(E)-\frac{f}{q} \frac{1}{\bar{B}(E)}=\nu_{A}(E)-\left[1+\frac{f}{q}\right] \frac{1}{\bar{B}(E)}=\widetilde{\varphi}_{A}\left(E, \frac{f}{q}\right)
$$

Thus the necessary and sufficient condition for this regime are ${ }^{5}$

$$
\varphi<\operatorname{Min}\left[\widetilde{\varphi}_{A}\left(E, \frac{f}{q}\right), \varphi_{0}^{O}\left(f, E, n, n^{*}, L\right)\right]
$$

Proposition 3.4. There exists an O-multinational equilibrium with no delegation if and only if

$$
\varphi<\operatorname{Min}\left[\widetilde{\varphi}_{A}\left(E, \frac{f}{q}\right), \varphi_{0}^{O}\left(f, E, n, n^{*}, L\right)\right]
$$

and the equilibrium number of subsidiaries is given by

$$
n_{I}^{O}=\frac{1}{1-\frac{\varphi}{Q_{O}(E)}}\left[\frac{\nu_{O}(E)-\varphi}{f} \frac{L}{\sigma}-\left(n+n^{*} \varphi\right)\right]
$$

The series of propositions (3.1),(3.2), (3.3) and (3.4) are illustrated in Figures $(3 \mathrm{a}),(3 \mathrm{~b})$, and $(3 \mathrm{c})$ and $(3 \mathrm{~d})$ where the different regions have been drawn in the plane $(\varphi, f / q)$ of trade freeness $\varphi$ and real fixed costs $f / q$. They reflect the importance of the relationship between local competition, local market size and the different possible regimes as a function of trade costs and fixed cost of FDI. We consider four cases : little local competition ( ie. $n<\frac{L}{\sigma q B_{P}(E)}-n^{*} \nu_{P}(E)$ ) ${ }^{6}$, intermediate local competition $\frac{L}{\sigma q B_{P}(E)}-n^{*} \nu_{P}(E)<n<\frac{L}{\sigma q B_{P}(E)}$ that allows for the existence of P-multinationals, intense competition $\frac{L}{\sigma q B_{P}(E)}<n<\frac{L}{\sigma q \bar{B}(E)}$, to finally the case with very intense competition $\frac{L}{\sigma q \bar{B}(E)}<n$.

\footnotetext{
${ }^{5}$ The value of $\varphi$ at which eventually $\varphi_{0}^{O}\left(\frac{f}{q}, E, n, n^{*}, L\right)$ is equal to $\widetilde{\varphi}_{A}\left(E, \frac{f}{q}\right)$ is given by $\widetilde{\varphi}_{O}(E)=\frac{\frac{1}{\bar{B}(E)} \frac{L}{\sigma q}-n}{n^{*}}$.

${ }^{6}$ Thus $n<\frac{L}{\sigma q B_{P}(E)}-n^{*} \nu_{P}(E)<\frac{L}{\sigma q \bar{B}(E)}-n^{*} \nu_{A}(E)<\frac{L}{\sigma q \bar{B}(E)}-n^{*} \nu_{O}(E)$. Therefore $\widetilde{\varphi}_{A}\left(E, \frac{f}{q}\right)<\varphi_{0}^{O}\left(f, E, n, n^{*}, L\right), \widetilde{\varphi}_{m}\left(E, \frac{f}{q}\right)<\varphi_{0}^{A}\left(\frac{f}{q}, E, n, n^{*}, L\right)$ and $\widetilde{\varphi}_{P}\left(E, \frac{f}{q}\right)<$ $\varphi_{0}^{P}\left(\frac{f}{q}, E, n, n^{*}, L\right)$ and $\widetilde{\varphi}_{m}^{0}(E)>\varphi_{0}^{P}\left(\frac{f}{q}, E, n, n^{*}, L\right)$ for all $f / q$
} 
In the first case, all the different regimes are possible and the profitability constraint of access to the local market through FDI is never binding for the A and the $\mathrm{O}$ regimes (ie. the constraint that $n_{I}>0$ is only separating the $\mathrm{P}$-multinational firm and exports as a strategy to enter the local market). In the intermediate competition case, P-multinationals are possible but the $\varphi_{0}^{P}$ curve is not always above the $\widetilde{\varphi}_{P}$ curve. In the intense competition case, however, P-multinationals are not possible (and potentially the range of parameters for A-multinationals is reduced). Finally, for very intense local competition, A-multinationals are not an equilibrium and only the O-multinational firm is the alternative option to exporting to the local market.

\section{Comparative Statics}

Our analysis allows us to discuss the impact of changes in various parameters of the model on the structure of delegating power inside the multinational corporation. Consider first the effect of trade costs and fixed costs of FDI on the allocation of power inside multinational firm. To illustrate this in the starkest way, it is useful to concentrate on the case depicted in Figure ("a) with $n<\frac{L}{\sigma q B_{P}(E)}-$ $n^{*} \nu_{P}(E)$ and redrawn in Figure 4 . For sufficiently low trade costs (large values of $\varphi$ ) and sufficiently large fixed costs of FDI, the export strategy dominates the establishment of a foreign subsidiary. Hence, for values of $\varphi$ and $f / q$ above the curve $\varphi=\varphi_{0}^{P}\left(\frac{f}{q}, E, n, n^{*}, L\right)$, there is no FDI in the local market.

\subsection{Trade costs}

Figure 4 also shows how, the internal organization of the multinational subsidiary depends on trade frictions and the fixed costs of FDI. Typically for a given fixed cost $f / q$ in a zone of profitable FDI, an increase in trade frictions (ie. a reduction in $\varphi$ ) from a point like $\mathrm{H}$ to a point like $\mathrm{L}$ leads to different degrees of delegation of power inside the multinational firm.

More precisely, when trade costs are low, exports profits are relatively high. In equilibrium, the FDI strategy to access the local market needs to provide as well a relatively high profit level to be a viable alternative to exports. Now, for high level of recurrent profits of the multinational firm, there is no trade-off 
between delegation and control inside the multinational firm. As proposition (?) shows, in such a case, local managers are induced to take sufficient initiatives under centralized control at the headquarter level. Hence, a foreign subsidiary optimal mode of organization will be a P-multinational.with full initiative when $\varphi>\widetilde{\varphi}_{P}\left(E, \frac{f}{q}\right)$. As well, a P-multinational organization with less than full but

sufficient high initiative will still be preferred in the region $\widetilde{\varphi}_{m}\left(E, \frac{f}{q}\right)<\varphi<$ $\widetilde{\varphi}_{P}\left(E, \frac{f}{q}\right)$.

With increasing trade costs (when $\varphi$ keeps decreasing), however, equilibrium profits from exports are further reduced, and as well the equilibrium value of profits of the alternative FDI strategy. At such profits levels, the P-multinational is not able to sustain enough initiative of local management of the subsidiary. It becomes then profitable to induce this managerial initiative through delegation of power to the subsidiary and an A-multinational firm with full initiative emerges as the optimal mode of FDI. Delegation power occurs indeed for intermediate values of $\varphi$ in the region $\widetilde{\varphi}_{A}\left(E, \frac{f}{q}\right)<\varphi<\widetilde{\varphi}_{m}\left(E, \frac{f}{q}\right)$.

Finally, when trade frictions become very high (ie. $\left.\varphi<\widetilde{\varphi}_{A}\left(E, \frac{f}{q}\right)\right)$, then equilibrium profits from exporting and FDI are low. Local managers in foreign subsidiaries cannot be induced to take any meaningful initiative even when power is delegated to them. In such a case, again there is no tradeoff between initiative and control. The optimal organization is the O-multinational firm with decision power fully centralized at the multinational headquarter's level.

\subsection{Fixed costs}

Alternatively, Figure 4 can be discussed in terms of comparative statics on fixed costs of establishing a foreign subsidiary, for a given value of $\varphi$. An increase in the fixed cost $f / q$ makes the organizational mode moves from a point like $\mathrm{G}$ to a point like $\mathrm{I}$ in Figure 5. For low levels of fixed costs, many multinational firms enter the local market. Local competition therefore is tough and recurrent equilibrium profits of foreign subsidiaries are low, leading to an O-multinational equilibrium. When fixed costs keep increasing, local competition becomes less intense leading to an increase in equilibrium profits in foreign subsidaries. As stakes inside the multinational keep increasing, we have sucessively the different optimal organizational modes of power as describes by proposition (?). Hence, the 
A-multinational will emerge for intermediate values of $f / q$ and theP-multinational will emerge for larger values of $f / q$.

\subsection{Information}

In this model, collection of information on local production conditions is central to the FDI decision and how to organize the local subsidiary. In particular, we can investigate the impact on FDI of a change in the efficiency of the technology of information $E$ of the headquaters and $\bar{e}$ of the local subsidiary management. Again to avoid some cumbersome taxonomic discussion, let us again concentrate on the configuration of parameters with $n<\frac{L}{\sigma q B_{P}(E)}-n^{*} \nu_{P}(E)$.

\section{a) Headquarter's information technology}

Consider then the effect of a change in $E$ on the various relevant thresholds $\varphi_{0}^{P}\left(\frac{f}{q}, E, n, n^{*}, L\right), \widetilde{\varphi}_{P}\left(E, \frac{f}{q}\right), \widetilde{\varphi}_{m}\left(E, \frac{f}{q}\right)$, and $\widetilde{\varphi}_{A}\left(E, \frac{f}{q}\right)$. It is immediate to see that all the thresholds are increasing in $E$. Moreover (see the appendix)

$$
\frac{\partial}{\partial E}\left[\varphi_{0}^{P}\left(\frac{f}{q}, E, n, n^{*}, L\right)-\widetilde{\varphi}_{P}\left(E, \frac{f}{q}\right)\right]>0
$$

and

$$
\frac{\partial}{\partial E}\left[\widetilde{\varphi}_{P}\left(E, \frac{f}{q}\right)-\widetilde{\varphi}_{m}\left(E, \frac{f}{q}\right)\right]>0
$$

while

$$
\frac{\partial}{\partial E}\left[\widetilde{\varphi}_{m}\left(E, \frac{f}{q}\right)-\widetilde{\varphi}_{A}\left(E, \frac{f}{q}\right)\right]<0
$$

Hence, for a given value of trade costs, regions with P-multinationals (with full and partial initiative) as well as the region with O-multinationals expand, while the region with A-multinationals shrinks. Intuitively, more efficient information technologies available to multinational heaquarters make it more likely to have FDI with a centralized structure and reduces the scope for delegation of power to the local level. 


\section{b) Subsidiary's information technology}

Conversely, consider now an improvement in the information technology $\bar{e}$ of local management. We immediately have (see the appendix) that

$$
\begin{gathered}
\frac{\partial}{\partial \bar{e}}\left[\varphi_{0}^{P}\left(\frac{f}{q}, E, n, n^{*}, L\right)\right]>0 \\
\frac{\partial}{\partial \bar{e}}\left[\varphi_{0}^{P}\left(\frac{f}{q}, E, n, n^{*}, L\right)-\widetilde{\varphi}_{P}\left(E, \frac{f}{q}\right)\right]>0 \\
\frac{\partial}{\partial \bar{e}}\left[\widetilde{\varphi}_{P}\left(E, \frac{f}{q}\right)-\widetilde{\varphi}_{m}\left(E, \frac{f}{q}\right)\right]>0 \\
\frac{\partial}{\partial \bar{e}}\left[\widetilde{\varphi}_{m}\left(E, \frac{f}{q}\right)-\widetilde{\varphi}_{A}\left(E, \frac{f}{q}\right)\right]>0
\end{gathered}
$$

and

$$
\frac{\partial}{\partial \bar{e}}\left[\widetilde{\varphi}_{A}\left(E, \frac{f}{q}\right)\right]<0
$$

Thus, the more efficient the information technology of the local manager, the more likely is a multinational with an organization form that keeps the manager's initiative alife in the subsidiary (a P-multinational with full or partial initiative and an A-multinational) and the less likely are O-multinationals.

We close this section by examining the role of information technology on the equilibrium number of multinationals in the local market. The effect is ambiguous. This can be seen from differentiating (3.8), (3.12), (3.13), or (3.16). On the one hand, a better headquarter or local management information technology will improve the expected profitability to establish a productive subsidiary in the local market as $\nu_{P}(E), \nu_{A}(E)$ and $\nu_{O}(E)$ are all increasing in $E$ and $\bar{e}$. On the other hand, as more subsidiaries are successfully producing, competition on the local market becomes more intense and this tends to reduce FDI profits and entry into the local market. 


\section{Local Competition and Market Size with fixed and free Entry}

\subsection{Local Competition and Market Size}

The previous characterization of the equilibrium multinational organizations shows how local competition and market size affects the allocation of power inside multinationals. More precisely, consider first for a fixed market size $L$ how different values of $n$ affect the possible modes of multinational organization in the local market. We may illustrate these results in Figure 6. Two threshold levels of $n$ are crucial $n_{P}=\frac{L}{\sigma q B_{P}(E)}$ and $n_{A}=\frac{L}{\sigma q \bar{B}(E)}$. For little local competition, $n<n_{P}$, all forms of multinational organizations are possible depending on the values of trade and fixed costs (as discussed in the previous section). However, when $n_{P}<n<n_{A}$, local competition becomes tougher, reducing the potential recurrent profits of a multinational subsidiary to a point at which local managers cannot be induced to take initiatives under a centralized decision power structure. In such a case, only A-multinationals and O-multinationals can emerge. When competition becomes even tougher (ie. $n>n_{A}$ ) then, delegation to local managers cannot induce initiative inside the subsidiary, as the stakes of the firm are too small. In that case, local power is irrelevant to the multinational and the O-multinational is the only feasable equilibrium.

Alternatively, we can take the number of local firms $n$ as fixed and consider changes in the local market size $L$. The two thresholds market sizes $L_{A}=$ $n \sigma q \bar{B}(E)$ and $L_{P}=n \sigma q B_{P}(E)$ become important. When the local market is very small (ie. $L<L_{A}$ ) only O-multinationals are possible. When the local market becomes larger, A-multinationals with delegation of power to the subsidiary emerge as additional equilibrium organization. Finally, in large markets $L>L_{P}$, the centralized P-multinational with initiative may become as well viable organization.

\subsection{Free Entry Long run Competition}

So far we have assumed that there is no entry by domestic firms. However, in the long run a change in market size, triggers entry or exit by domestic firms, affecting endogenously the degree of local competition and thus the allocational of power inside multinational firms. 
In this section we investigate this issue in more detail. For this, assume that to enter the local market, local firms have to pay a fixed cost $F$

Assume further that the number of foreign firms remains fixed at $n^{*}$. Profits by local firms are equal to

$$
\pi_{L}=\pi_{I}=\frac{L}{\sigma} \frac{c^{1-\sigma}}{\left(n+n_{I}\right) c^{1-\sigma}+n_{X}\left(c^{*} \tau\right)^{1-\sigma}}=\frac{L}{\sigma} \frac{1}{n+n_{I}+n_{X} \varphi}
$$

Hence, the free entry condition for local firms is

$$
\frac{L}{\sigma} \frac{1}{n+n_{I}+n_{X} \varphi}=F
$$

Combined with the condition of arbitrage between multinational entry and exports, it is easy to see that in general, foreign firms will all adopt FDI or exports, (ie. there is a corner solution in terms of the equilibrium number of foreign firms undertaking FDI or exports). More specifically, we have that

$$
\begin{aligned}
& F\left(\nu_{i}(E)-\varphi\right)-q I_{i}>f \Rightarrow n_{X}=0 \text { and } n_{I}=n^{*} Q_{i} \\
& F\left(\nu_{i}(E)-\varphi\right)-q I_{i}<f \Rightarrow n_{I}=0 \text { and } n_{X}=n^{*} \\
& F\left(\nu_{i}(E)-\varphi\right)-q I_{i}=f \Rightarrow n_{X}+\frac{n_{I}}{Q_{i}}=n^{*}
\end{aligned}
$$

for the different possible multinational regimes with hierarchical structures $i=P, A$ or $O$.and $I_{i}$ taking value 1 for $i=P, A$ and 0 for $i=O$.. When FDI is an equilibrium solution, the equilibrium organizational structure of the multinationals operating in the country depends on the value of operating profits of the subsidiary $B=F$ and how it compares with the thresholds $q \bar{B}(E)$ and $q B_{P}(E)$.

The equilibrium number of local firms $n^{e}$ is given by:

$n^{e}=\frac{L}{\sigma F}-n^{*} \varphi$ when there is no FDI

$=\frac{L}{\sigma F}-n^{*} Q_{i}(E)$ when there is FDI with organizational mode $i \in\{P ; M, O\}$

From this discussion follows immediately the following proposition:

Proposition 5.1. i) Assume $F<q \bar{B}(E)$, then if $F \geq f /\left(\nu_{O}(E)-\varphi\right)$ : all foreign firms enter as $O$-multinationals, the equilibrium number of local firms is $n^{e}=$ $\frac{L}{\sigma F}-n^{*} E$. Otherwise all foreign firms undertake exports and $n^{e}=\frac{L}{\sigma F}-n^{*} \varphi$. 
ii) Assume $q \bar{B}(E) \leq F<q B_{P}(E)$, then if $F>(f+q) /\left(\nu_{A}(E)-\varphi\right)$, all foreign firms enter as $A$-multinationals, the equilibrium number of local firms is $n^{e}=\frac{L}{\sigma F}-n^{*}(E+(1-E) \bar{e})$. Otherwise, all foreign firms undertake exports and $n^{e}=\frac{L}{\sigma F}-n^{*} \varphi$.

iii) Assume $q B_{P}(E)<F$, then if $F>(f+q) /\left(\nu_{P}(E)-\varphi\right)$, all foreign firms enter as $P$-multinationals with full initiative, and the equilibrium number of local firms is $n^{e}=\frac{L}{\sigma F}-n^{*}(E+(1-E) \bar{e})$. Otherwise all foreign firms undertake exports and $n^{e}=\frac{L}{\sigma F}-n^{*} \varphi$. $^{7}$

Proposition (5.1) is illustrated in Figure 6 in the space $(F, f)$ of fixed costs of entry of the local firms and the multinationals. Region $O$ represents the region of $O$-multinational firms. It is defined by the line $f=F\left(\nu_{O}(E)-\varphi\right)$ and $F=q \bar{B}(E)$. Region $A$ reflects the case of $A$-multinationals. It is defined by $q \bar{B}(E) \leq F<$ $q B_{P}(E)$ and $f<F\left(\nu_{A}(E)-\varphi\right)-q .{ }^{8}$ Region $P$ defined by $q B_{P}(E)<F$ and $f<F\left(\nu_{E}(E)-\varphi\right)-q$ gives the $\mathrm{P}$-multinational outcome. The remaining region $\mathrm{X}$ describes the situation with foreign exports. Clearly such a region prevails when the fixed cost of FDI $f$ is relatively high compared to the fixed cost of entry $F$ of domestic firms. Hence, multinationals should have a substancial entry cost advantage over local firms to allow their entry into the market. The larger the fixed cost of entry of local firms, the smaller the degree of competition in this market and the larger the rents that can be captured by multinationals. As the stakes inside foreign subsidiaries increase with $F$, the optimal organizational mode of power allocation inside the multinational moves from a O-multinational (with no local managerial initiative inside the multinational subsidiary) to an A-multinational (with delegation of power to the local subsidiary manager) to finally a P-multinational (with centralized power at the headquarter level and full initiative of the subsidiary manager).

\footnotetext{
${ }^{7}$ The case of P-multinationals with partial initiative occurs in this local free entry case when $F=q B_{P}(E)$, which is of measure zero in our parameter space.

${ }^{8}$ Note that at $F=q \bar{B}(E)$

$$
\begin{aligned}
F\left(\nu_{A}(E)-\varphi\right)-q & =\frac{q}{(K-E) \bar{e}}[(E+(K-E) \bar{e})-\varphi]-q \\
& =\frac{q}{(K-E) \bar{e}}[E-\varphi]=F\left(\nu_{O}(E)-\varphi\right)
\end{aligned}
$$

Hence it can be observed that the line $f=F\left(\nu_{O}(E)-\varphi\right)$ crosses the line $f=F\left(\nu_{A}(E)-\varphi\right)-q$ at $F=q \bar{B}(E)$.
} 
In this model, the local market size $L$ has no effect on the optimal mode of multinational organization when there is local free entry. Multinational organization depends only on the technology parameters $E, K, \bar{e}$ of the multinational, and the local cost of entry $F / q$ in terms of local skilled labor. The reason is that an increase in the local market size $L$ is matched by an accompanying entry of local firms, leaving the operating profits of foreign multinationals unchanged in the long run. For the same reason, transport costs (as captured by $\varphi$ ) do not affect the optimal mode of multinational organization as long as they do not induce foreign firms to give up serving the local market through FDI.

\section{Conclusions}

In this paper we examine how market competition, trade costs and market size interact with firms' decision to serve a local market through exports or FDI and most importanty how it affects the optimal mode of multinational organization. Market competition changes managerial behavior and this in turn affects the allocation of power inside the multinational corporation. With more intense competition, the conflict of interests between different layers of management (headquarters versus local subsidiary) may become more costly to a multinational firm. More intense competition may reduce the stakes that local subsidiaries can get. This in turn may reduce the motivation of local managers to engage in the multinational firm. Under these circumstances, it is worthwile for multinational headquarters to change the mode of organization of production of their subsidiaries and to delegate decision power to the multinational subsidiary manager to stimulate her initiative. However, the empowerment of the subsidiary manager opens up the possibility for opportunism which is costly to the multinational firm. The optimal allocation of power between headquarters and the multinational subsidiary involves a trade-off between initiative and control. We find that for intermediate levels of local competition managers of subsidaries are given most significant autonomy in the decision how to run the firm. After characterizing the equilibrium organizational mode of multinational firms in a given local market, the paper investigated how changes in fixed costs of FDI entry, trade costs, the number of local competitors and the size of the local market affect the power allocatio in the multinational corporation. The paper predicts that delegation of power to local subsidiary management is most likely when these variables lead to intermediate values of local competition. 

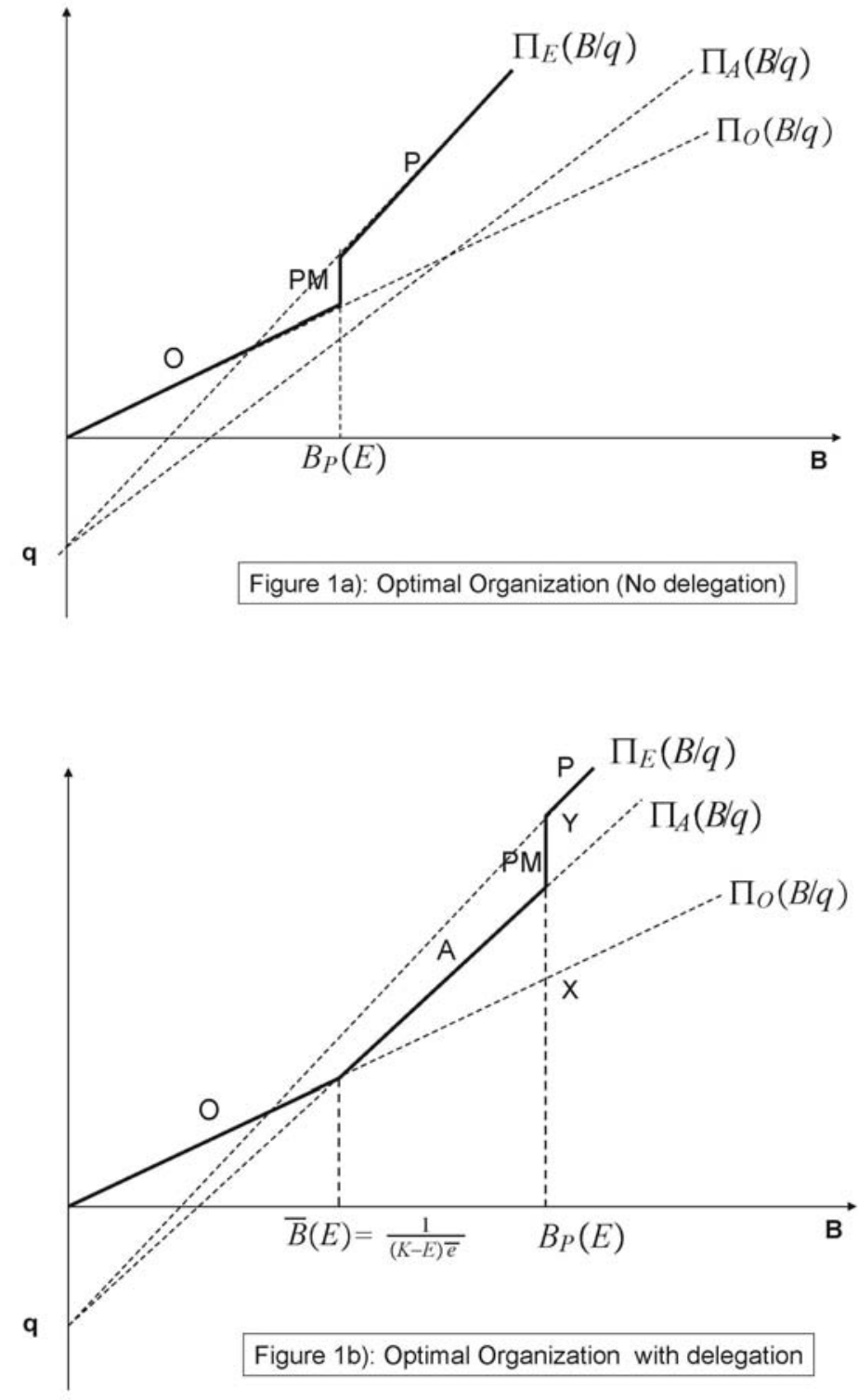

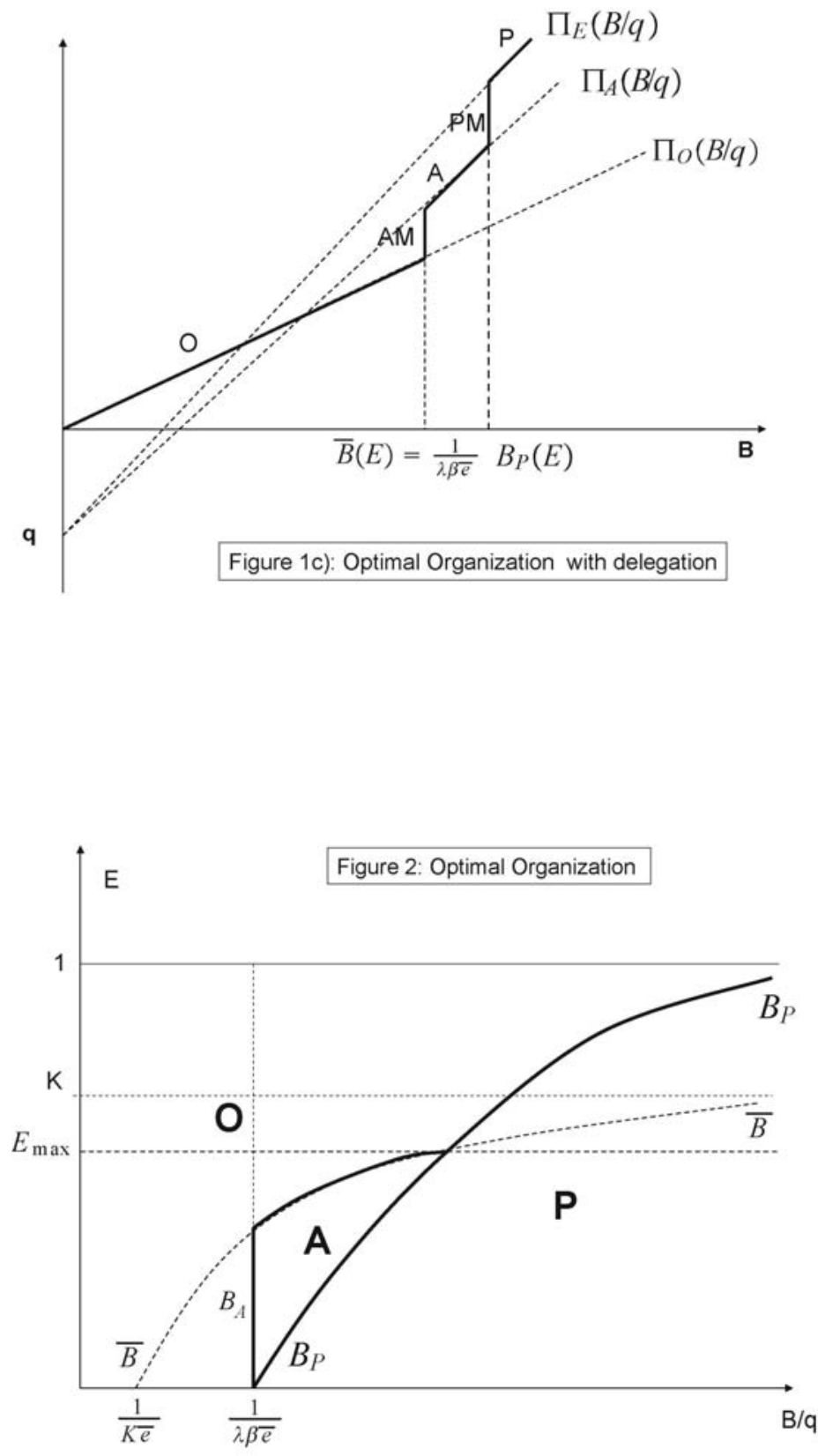


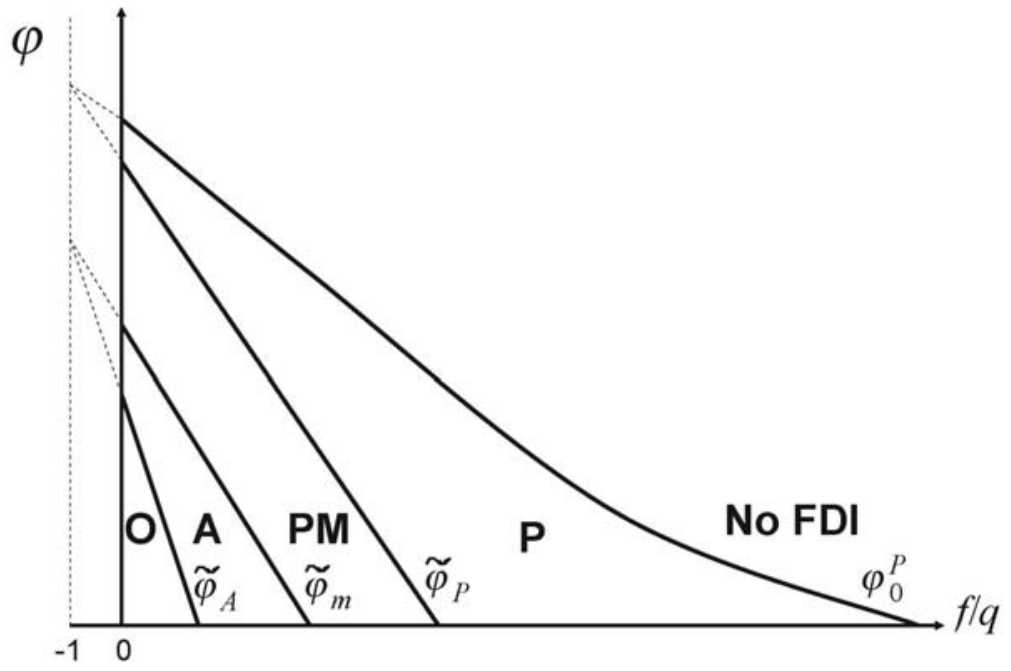

Figure 3a) Low local competition: $n<\frac{L}{\sigma q B_{P}(E)}-n^{*} v_{P}(E)$

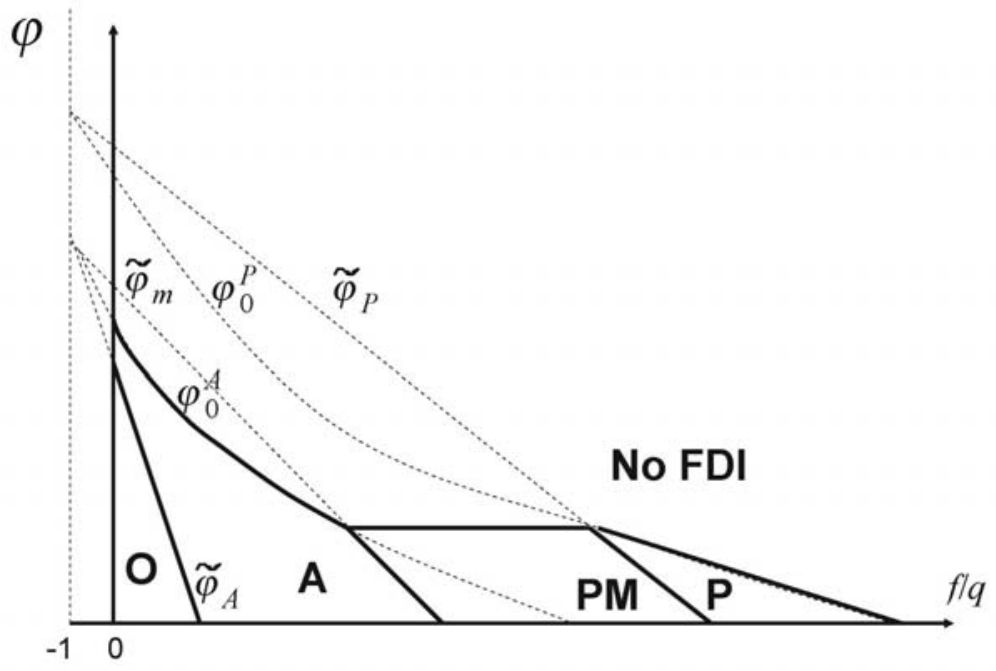

Figure 3b) Intermediate local competition : $\frac{L}{\sigma q B_{P}(E)}-n^{*} v_{P}(E)<n<\frac{L}{\sigma q B_{P}(E)}$ 


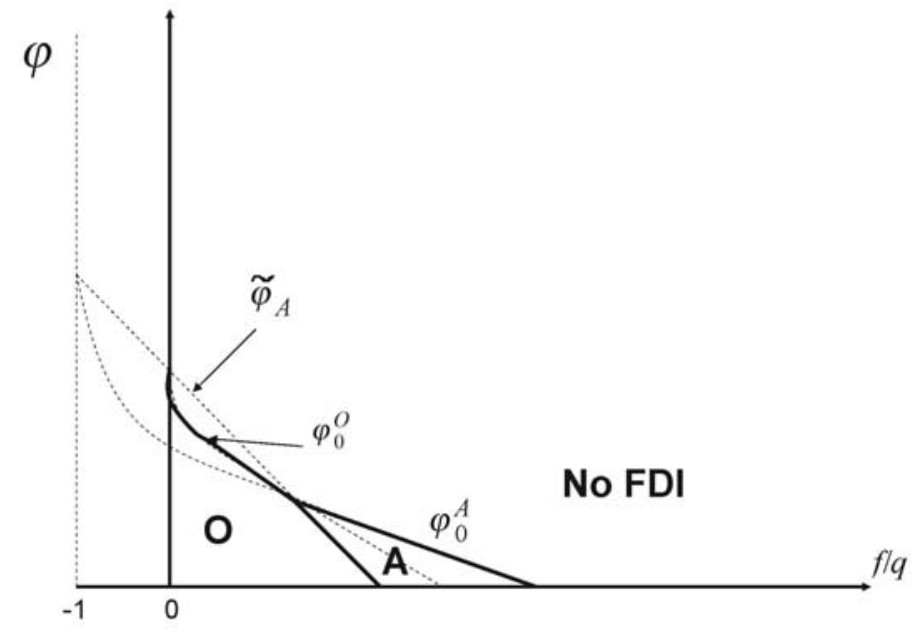

Figure 3c) large local competition: $\frac{L}{\sigma q B_{P}(E)}<n<\frac{L}{\sigma q \bar{B}(E)}$

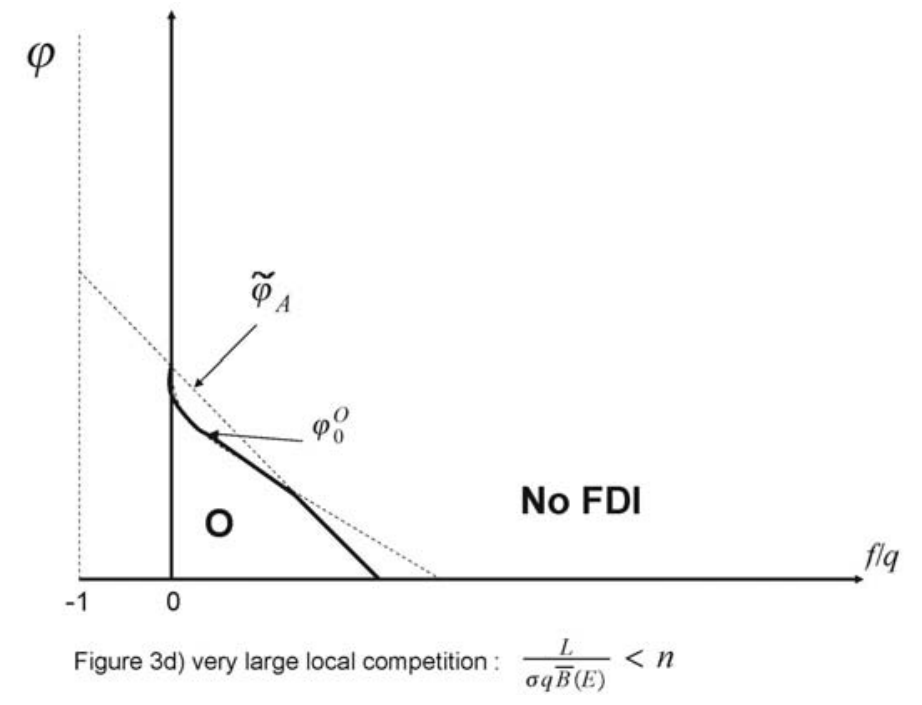



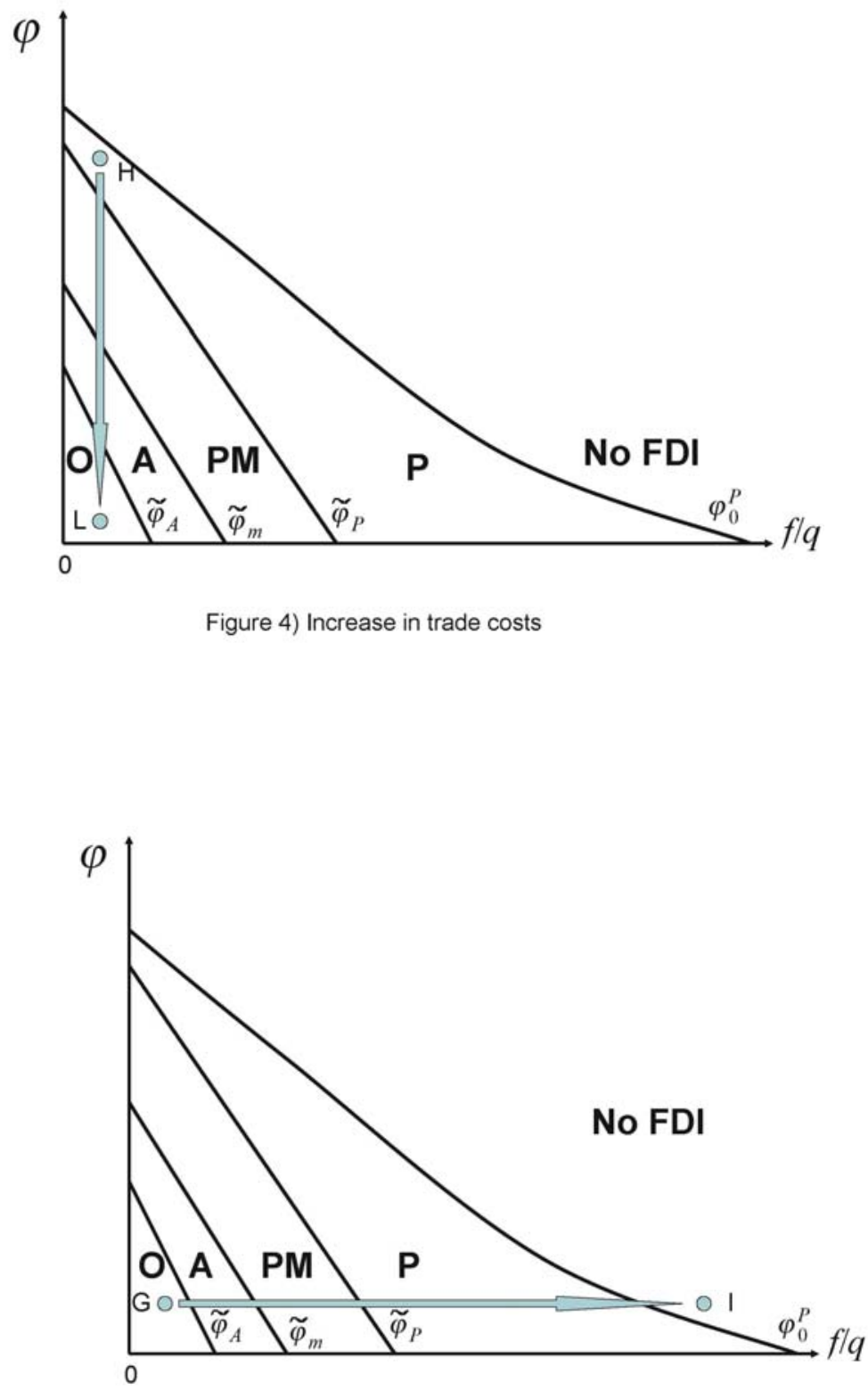

Figure 5) Increase in fixed costs 


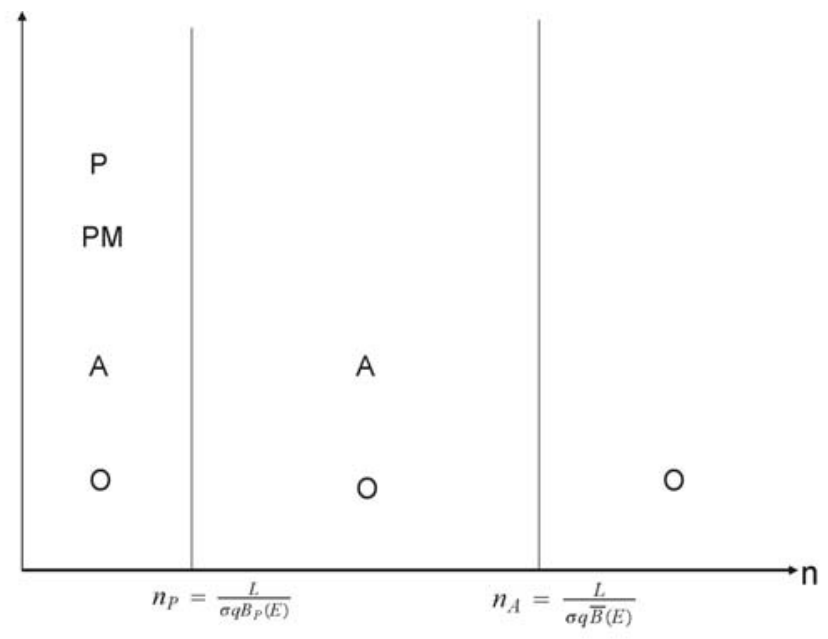

Figure 5) Modes of FDI delegation and local competition

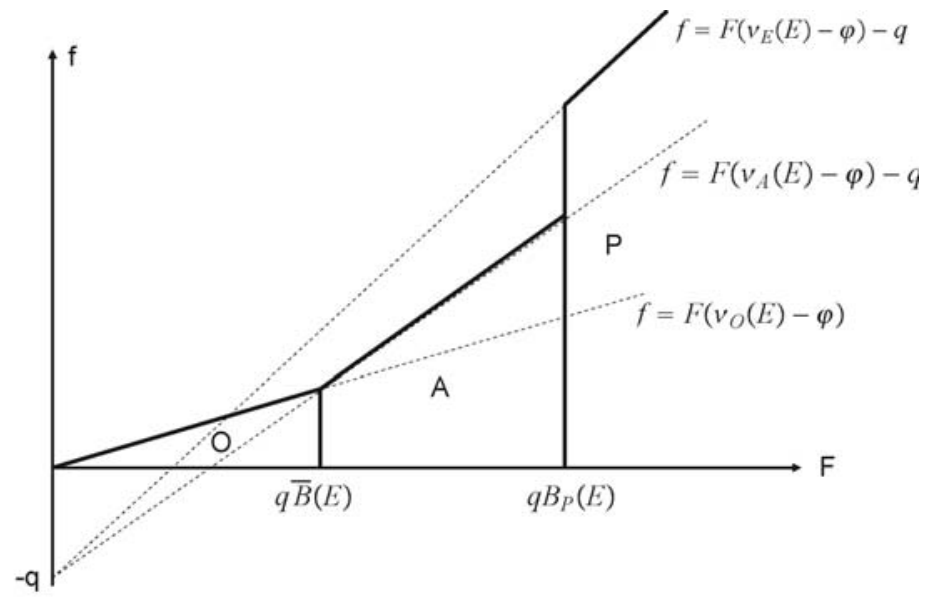

Figure 6: Free entry local competition and FDI organization 


\section{References}

[1] Antras, P. (2003), Firms, Contracts, and Trade Structure. Quarterly Journal of Economics 118:4, pp. 1375-1418.

[2] Antras, P. and E. Helpman (2004), Global Sourcing, Journal of Political Economy 112:3, pp552-580.

[3] Antras,P. L. Garicano, E. Rossi-Hansberg (2006), Offshoring in a Knowledge Economy, Quarterly Journal of Economics 121:1, pp. 31-77.

[4] Aghion, P. and J. Tirole (1997). Formal and Real Authority in Organizations. Journal of Political Economy. 105: 1. pp 1-29.

[5] Dixit, A. and J. E. Stiglitz (1977), Monopolistic Competition and Optimum Product Diversity. American Economic Review. 67, pp. 297-308.

[6] Grossman, S.J. and O. Hart (1986),The Costs and Benefits of Ownership: A Theory of Vertical and Lateral Integration. Journal of Political Economy. 94. pp. 691-719.

[7] Grossman, G. and E. Rossi-Hansberg (2006) Trading Tasks: A Simple Theory of Offshoring, Mimeo, Princeton University Press.

[8] Hart, O. and J. Moore (1990) Property Rights and the Nature of the Firm. Journal of Political Economy. 98. pp. 1119-1158.

[9] Krugman, P (1980) Scale Economies, Product Differentiation, and the Pattern of Trade. American Economic Review 70, pp 950-959

[10] Marin, D. and Th.Verdier (2003a),Globalization and the Empowerment of Talent, CEPR Discussion Paper No.4129, London.

[11] Marin, D. and Th. Verdier (2003b), Globalization and the 'New Enterprise', Journal of the European Economic Association, Papers and Proceedings, May.

[12] Marin, D. and Th. Verdier (2006), Corporate Hierarchies and the Size of Nations: Theory and Evidence, University of Munich and Paris School of Economics, Mimeo. 
[13] Marin D. and Th. Verdier (2007a), Power Inside the Firm and the Market: A General Equilibrium Approach, Journal of the European Economic Association, forthcoming

[14] Marin D. and Th. Verdier 2007b, Competing in Organizations: Firm Heterogeneity and International Trade, in: Helpman E. D. Marin, Th. Verdier (Eds.) The Organization of Firms in the Global Economy, Harvard University Press, forthcoming.

[15] J. McLaren. 2000. Globalization and Vertical Structure. American Economic Review. 90. pp. 1239-1254.

[16] Melitz, M. and G. Ottaviano (2005) Market Size, Trade and productivity, NBER Working Paper No. 11393.

[17] Puga, D. and D. Trefler (2005), Wake Up and Smell the Ginseng: The Rise of Incremental Innovation in Low-Wage Countries, University of Toronto, Mimeo. 


\section{Appendix 1: Existence conditions of a P-multinational Equilibrium} with partial initiative $h_{P}^{*} \in\left[\underline{h}_{P}, 1[\right.$

In this regime, as mentionned in the main text, we should have :

$$
\frac{L}{\sigma} \frac{1}{n+n^{*} \varphi+n_{I}\left(1-\frac{\varphi}{Q_{P}(E, h)}\right)}=q B_{P}(E)
$$

Denoting $\nu_{P}(E, h)=E+(1-E) \bar{e} h K$ for $h \in[0,1]$, the arbitrage condition between exports and FDI as a strategy to serve the local market writes as :

$$
\frac{L}{\sigma} \frac{\varphi}{n+n^{*} \varphi+n_{I}\left(1-\frac{\varphi}{Q_{P}(E, h)}\right)}=\frac{L}{\sigma} \frac{\nu_{P}(E, h)}{n+n^{*} \varphi+n_{I}\left(1-\frac{\varphi}{Q_{P}(E, h)}\right)}-q h-f
$$

Also the P-multinational with interior initiative should dominate the A-multinational with full initiative. This translates into the following condition:

$$
\frac{L}{\sigma} \frac{\nu_{P}(E, h)}{n+n^{*} \varphi+n_{I}\left(1-\frac{\varphi}{Q_{P}(E, h)}\right)}-q h \geq \frac{L}{\sigma} \frac{\nu_{A}(E)}{n+n^{*} \varphi+n_{I}\left(1-\frac{\varphi}{Q_{P}(E, h)}\right)}-q
$$

The first two conditions (??) and (6.2) give the necessary value of $h_{P}$ in that regime as the solution of

$$
B_{P}(E)\left[\nu_{P}\left(E, h_{P}\right)-\varphi\right]-h_{P}=\frac{f}{q}
$$

Consider then the function $\Theta(h)=B_{P}(E)\left[\nu_{P}(E, h)-\varphi\right]-h$. Simple differentiation shows that $\Theta(h)$ is increasing in $h$. From this, a necessary solution for a interior solution $h_{P}<1$ to (6.4) is that $\Theta(1)>f / q$ which can be rewitten as

$$
\varphi>\nu_{P}(E)-\frac{\left[1+\frac{f}{q}\right]}{B_{P}(E)}=\widetilde{\varphi}_{P}\left(E, \frac{f}{q}\right)
$$

As well substitution of (??) and (6.2) into (6.3) gives the following necessary condition for that regime:

$$
\frac{f}{q}>B_{P}(E)\left[\nu_{A}(E)-\varphi\right]-1
$$


which can be rewritten as

$$
\varphi>\widetilde{\varphi}_{m}\left(E, \frac{f}{q}\right)=\nu_{A}(E)-\left[1+\frac{f}{q}\right] \frac{1}{B_{P}(E)}
$$

- Reciprocally assume that

$$
\widetilde{\varphi}_{m}\left(E, \frac{f}{q}\right)<\varphi<\widetilde{\varphi}_{P}\left(E, \frac{f}{q}\right)
$$

holds. Then $\Theta(h)=f / q$ has a unique interior solution $\left.h_{P}^{*} \in\right] 0,1[$. Indeed $\Theta(1)>$ $f / q$ as $\varphi<\widetilde{\varphi}_{P}\left(E, \frac{f}{q}\right)$, Also $\Theta(0)=B_{P}(E)[E-\varphi]<B_{P}(E)\left[\nu_{A}(E)-\varphi\right]-1<f / q$ when $\varphi>\widetilde{\varphi}_{m}\left(E, \frac{f}{q}\right)$.

Now from (??), the equilibrium number of multinationals in this regime is given by :

$$
n_{I}^{m}=\frac{1}{1-\frac{\varphi}{Q_{P}\left(E, h_{P}\right)}}\left[\frac{1}{B_{P}(E)} \frac{L}{\sigma q}-\left(n+n^{*} \varphi\right)\right]>0
$$

which is positive when $\frac{1}{B_{P}(E)} \frac{L}{\sigma q}-\left(n+n^{*} \varphi\right)>0$ or

$$
\varphi<\widetilde{\varphi}_{m}^{0}(E)=\frac{\frac{1}{B_{P}(E)} \frac{L}{\sigma q}-n}{n^{*}}
$$
is

Hence a necessary and sufficient condition for the existence of such a regime

$$
\widetilde{\varphi}_{m}\left(E, \frac{f}{q}\right)<\varphi<\operatorname{Min}\left[\widetilde{\varphi}_{m}^{0}(E) ; \widetilde{\varphi}_{P}\left(E, \frac{f}{q}\right)\right]
$$

Clearly $\widetilde{\varphi}_{m}^{0}(E)>0$ for such a condition to define a non empty set of values of $\varphi$. Hence the condition

$$
n<\frac{1}{B_{P}(E)} \frac{L}{\sigma q}
$$

as the condition for the existence of a $\mathrm{P}$-multinational with interior initiatives. QED

Note finally that the eventual value of $\varphi$ such that $\varphi=\varphi_{0}^{P}\left(\frac{f}{q}, E, n, n^{*}, L\right)=$ $\widetilde{\varphi}_{P}\left(E, \frac{f}{q}\right)$ is determined by

$$
\varphi_{0}^{P}\left(\frac{f}{q}, E, n, n^{*}, L\right)=\widetilde{\varphi}_{P}\left(E, \frac{f}{q}\right)
$$


or the value of $f / q$ such that:

$$
\frac{\frac{L}{\sigma q} \nu_{P}(E)-\left[1+\frac{f}{q}\right] n}{\frac{L}{\sigma q}+\left[1+\frac{f}{q}\right] n^{*}}=\nu_{P}(E)-\frac{\left[1+\frac{f}{q}\right]}{B_{P}(E)}
$$

which after manipulation gives:

$$
\varphi=\frac{\frac{1}{B_{P}(E)} \frac{L}{\sigma q}-n}{n^{*}}=\widetilde{\varphi}_{m}^{0}(E)
$$

\section{Appendix 2: Changes in the information technology}

For the information technology of a multinational headquarter, simple differentiation by $E$ gives:

$$
\begin{aligned}
\frac{\partial}{\partial E}\left[\varphi_{0}^{P}\left(\frac{f}{q}, E, n, n^{*}, L\right)-\widetilde{\varphi}_{P}\left(E, \frac{f}{q}\right)\right] & =\left[\frac{\frac{L}{\sigma q}}{\frac{L}{\sigma q}-\left[1+\frac{f}{q}\right] n^{*}}-1\right](1-\bar{e} K)+\left[1+\frac{f}{q}\right] \beta \lambda \bar{e} \\
& =\frac{\left[1+\frac{f}{q}\right] n^{*}}{\frac{L}{\sigma q}-\left[1+\frac{f}{q}\right] n^{*}}(1-\bar{e} K)+\left[1+\frac{f}{q}\right] \beta \lambda \bar{e}>0
\end{aligned}
$$

and

$$
\begin{gathered}
\frac{\partial}{\partial E}\left[\widetilde{\varphi}_{P}\left(E, \frac{f}{q}\right)-\widetilde{\varphi}_{m}\left(E, \frac{f}{q}\right)\right]=(1-\bar{e} K)-(1-\bar{e})=\bar{e}(!-K)>0 \\
\frac{\partial}{\partial E}\left[\widetilde{\varphi}_{m}\left(E, \frac{f}{q}\right)-\widetilde{\varphi}_{A}\left(E, \frac{f}{q}\right)\right]=\left[1+\frac{f}{q}\right][\beta \lambda \bar{e}-\bar{e}]<0
\end{gathered}
$$

For the information technology of a local management, simple differentiation by $\bar{e}$ gives:

$$
\frac{\partial}{\partial \bar{e}}\left[\varphi_{0}^{P}\left(\frac{f}{q}, E, n, n^{*}, L\right)\right]=(1-E) K \frac{\frac{L}{\sigma q}}{\frac{L}{\sigma q}-\left[1+\frac{f}{q}\right] n^{*}}>0
$$




$$
\begin{aligned}
\frac{\partial}{\partial \bar{e}}\left[\varphi_{0}^{P}\left(\frac{f}{q}, E, n, n^{*}, L\right)-\widetilde{\varphi}_{P}\left(E, \frac{f}{q}\right)\right] & =(1-E) K\left[\frac{\left[1+\frac{f}{q}\right] n^{*}}{\frac{L}{\sigma q}-\left[1+\frac{f}{q}\right] n^{*}}\right]+\left[1+\frac{f}{q}\right] \beta \lambda(1-E)>0 \\
\frac{\partial}{\partial \bar{e}}\left[\widetilde{\varphi}_{P}\left(E, \frac{f}{q}\right)-\widetilde{\varphi}_{m}\left(E, \frac{f}{q}\right)\right]= & (1-E) K-(K-E)=E(1-K)>0 \\
\frac{\partial}{\partial \bar{e}}\left[\widetilde{\varphi}_{m}\left(E, \frac{f}{q}\right)-\widetilde{\varphi}_{A}\left(E, \frac{f}{q}\right)\right] & =\left[1+\frac{f}{q}\right][-\beta \lambda(1-E)+(K-E)] \\
& =\left[1+\frac{f}{q}\right][1-\lambda-(1-\beta \lambda) E]>0 \\
\frac{\partial}{\partial \bar{e}}\left[\widetilde{\varphi}_{A}\left(E, \frac{f}{q}\right)\right]=(K & -E)-\left[1+\frac{f}{q}\right](K-E)<0
\end{aligned}
$$

QED. 